\title{
The NUADU experiment on TC-2 and the first Energetic Neutral Atom (ENA) images recorded by this instrument
}

\author{
S. McKenna-Lawlor ${ }^{1}$, L. Li ${ }^{2}$, S. Barabash ${ }^{3}$, K. Kudela ${ }^{4}$, J. Balaz ${ }^{1}$, I. Strharsky ${ }^{1}$, K. Brinkfeldt ${ }^{3}$, H. Gunell ${ }^{1,3}$, \\ C. Shen ${ }^{2}$, J. Shi ${ }^{2}$, J.-B. Cao ${ }^{2}$, Q. Zong ${ }^{2}$, S-Y. Fu ${ }^{5}$, E. C. Roelof ${ }^{6}$, P. C. Brandt ${ }^{6}$, and I. Dandouras \\ ${ }^{1}$ Space Technology Ireland, National University of Ireland, Maynooth, Co. Kildare, Ireland \\ ${ }^{2}$ Centre for Space Science and Applied Research of the Chinese Academy of Sciences, Beijing, China \\ ${ }^{3}$ Swedish Institute of Space Physics, Kiruna, Sweden \\ ${ }^{4}$ Institute of Experimental Physics, Kosice, Slovakia \\ ${ }^{5}$ School of Earth and Space Sciences, Peking University, Beijing, China \\ ${ }^{6}$ The Johns Hopkins University, Applied Physics Laboratory, Laurel, Maryland, USA \\ ${ }^{7}$ Centre d'Etude Spatiale des Rayonnements, Toulouse, France
}

Received: 18 February 2005 - Revised: 26 September 2005 - Accepted: 29 September 2005 - Published: 8 November 2005

Part of Special Issue "Double Star - First Results"

\begin{abstract}
The Earth's ring current and how it responds to varying interplanetary conditions is described and an account provided of the production of Energetic Neutral Atoms (ENAs) in the geo-corona. Also, the potential to remotely monitor, on a global scale, the temporal and spatial evolution of magnetospheric plasma populations through analysing ENA images recorded during magnetic storms/substorms is indicated. A technical account of the Energetic NeUtral Atom Detector Unit NUADU aboard China's TC-2 mission (measurement range $45->158 \mathrm{keV}$ ) follows, together with an account of the scientific objectives of NUADU, both in stand-alone mode and in the context of multi-point imaging. Low altitude ENA emissions recorded by NUADU during south polar passages of TC-2 at the time of a moderate magnetic storm in September 2004, as well as bright ring current emissions recorded in November 2004 during a major geomagnetic storm, are presented and discussed in the context of various, accompanying, terrestrial disturbances. Also, ENA observations of the November 2004 ring current imaged simultaneously by TC-2/NUADU and by IMAGE/HENA (viewing, respectively, from the Northern and Southern Hemispheres), are compared.
\end{abstract}

Keywords. Magnetospheric Physics (Solar windmagnetosphere interactions; Magnetospheric configuration and dynamics)

\section{Introduction}

The Double Star Mission has its origin in an interagency agreement between the Chinese and European Space Agen-

Correspondence to: S. McKenna-Lawlor

(still@nuim.ie) cies whereby two spacecraft from China, one flying in a polar and the other in an equatorial orbit, provide scientific support for experiments conducted aboard the four spacecraft of the European Space Agency's Cluster Mission.

Of relevance to the present paper is the polar satellite (TC-2) which was launched at 15:15 UT on 25 July 2004 to monitor physical processes taking place over the terrestrial magnetic poles. TC-2 performs an elliptical orbit $(700 \times 39000 \mathrm{~km})$ around the Earth at an inclination of $90^{\circ}$, and traverses the Southern Polar Cap, the Southern Auroral Oval, the Radiation Belts, the Plasmasphere, the Northern Cusp and the Tail Lobes. Its perigee is above the Southern Polar Cap and the periodicity of the spacecraft is $11.7 \mathrm{~h}$. Included in the payload is an Energetic NeUtral Atom (ENA) imager NUADU, which is designed to detect ENAs in the energy range $45->158 \mathrm{keV}$.

In the present paper an account is provided (Sect. 2) of the Earth's ring current and its response to varying interplanetary conditions. In Sect. 3 the production in the Earth's magnetosphere of Energetic Neutral Atoms (ENAs) is discussed. In Sect. 4 the NUADU instrument is introduced and described. In Sect. 5 its scientific objectives, in both stand-alone mode and in the context of multi-point ENA imaging, are indicated. In Sect. 6 ENA images recorded by NUADU during two different episodes of geomagnetic storm activity in September and November 2004 are presented and discussed in the context of contemporaneous, background, solar related terrestrial disturbances.

A comparison is made between images of the November ring current recorded simultaneously by NUADU and by the High Energy Neutral Atom (HENA) imager (Mitchell et al., 2000) on board the IMAGE satellite (Burch, 2003). Section 7 contains general conclusions. 


\section{The ring current}

The solar wind and its embedded magnetic fields form the driving plasma environment in which the Earth's magnetosphere exists. The solar wind is highly dynamic and exhibits variations in its plasma and field properties with respect to their average values on time scales ranging from years (associated with the waxing and waning of the sunspot cycle), to intervals that can be as short as a fraction of a second (Kivelson and Russell, 1995).

Particle trapping occurs when an electrically charged particle is injected with an initial velocity, and at a certain angle, into the Earth's magnetic field and follows a helicoidal trajectory about, and along, a geo-magnetic field line, provided that its energy does not exceed the threshold necessary to permit trapping. When it spirals towards a region of higher field intensity, the particle experiences an induced electric field that accelerates its "cyclotron" motion transverse to the field line. Since the total energy of a particle cannot change in a static magnetic field, the increase in transverse kinetic energy that occurs is accompanied by a corresponding "slow-down" in the motion parallel to the field line. A point can eventually be reached at which all the parallel kinetic energy has been converted into transverse energy and the particle then reverses its parallel motion and spirals back in the opposite direction. In the case of the Earth's magnetic field, a particle can "bounce" back and forth between two such "mirror points" lying on opposite sides of the geomagnetic equator. Because the terrestrial magnetic field is not uniform and its field lines are curved, a representative particle undergoes, in addition, a drift in longitude around the Earth such that electrons, due to their negative charge, drift eastwards while positively charged protons drift westward. Lower energy ions ( $<$ few keV) drift eastwards with the electrons (see representative accounts in overviews by Northrop, 1963; Roederer, 1971 and Schulz and Lanzerotti, 1974). These currents are driven (see below) by pressure gradients and provide a net transport of charge (the ring current, Singer, 1957) in the Earth's equatorial plane that shows variable density at geocentric distances between, approximately, 2 and $9 R_{E}$ (Daglis et al., 1999).

The magnetic field $\left(j_{\perp}\right)$ of a plasma in equilibrium (such that the magnetic stress balances the particle pressure), can be represented by:

$j_{\perp}=\frac{\boldsymbol{B}}{B^{2}} \times\left[\nabla P_{\perp}+\left(P_{/ /}-P_{\perp}\right) \frac{\boldsymbol{B} \cdot \nabla}{B^{2}} \boldsymbol{B}\right]$,

where $\boldsymbol{B}$ is the local magnetic field vector, and $P_{/ /}$and $P_{\perp}$ are, respectively, the pressure tensor components parallel and perpendicular to the local magnetic field. The three pressure terms on the right side of the equation represent, in order, the particle pressure gradient; the field line curvature driven drift and the crowding of gyro-orbits inside a curved field line. The second and third terms is this expression vanish when the field lines are straight, and also when the particle distribution is isotropic (i.e. when $P_{/ /}=P_{\perp}$ ). In these cases the current system is established only by the particle pressure gradients. As noted by Baumjohann (1993), the contribution of electrons to the plasma pressure can usually be neglected since it is significantly less (by a factor of about seven), than that provided by protons.

Among the many solar related disturbances produced in the Earth's environment, magnetic storms are the most powerful. In the course of a large storm, up to $10^{17} \mathrm{~J}$ of energy can be dissipated at the Earth over a period of several days (Pollock et al., 2003). During substorms, considerably less total energy is released and the duration of these events is significantly shorter (approximately $3 \times 10^{15} \mathrm{~J}$ within an interval of the order of one hour, Baker et al., 1997).

A magnetic storm is characterized by the injection of ions into the trapping region of the magnetosphere $\left(L<\sim 7 \mathrm{R}_{E}\right)$. Decay to a rest state takes place within a few days. The storm time ion population is sufficiently energized that its pressure gradients stimulate the flow of an azimuthal ring current. This strong current near the magnetic equator (between 2 and $9 R_{E}$ ) depresses the Earth's magnetic field. It was demonstrated by Dessler and Parker (1959) and by Sckopke (1966) that the disturbance $\Delta B$ produced at the Earth's centre (which is frequently used as a diagnostic of space storms at the Earth), is proportional to the total energy of the ring current particles:

$\frac{\Delta B}{B_{0}}=-\frac{2 E}{3 E_{m}}$,

where $B_{0}$ is the average geomagnetic intensity at the equator; $E$ is the total energy of the ring current particles and $E_{M}=B_{0}^{2} R_{E}^{3} / 3=10^{18} \mathrm{~J}$ is the energy of the dipole field above the Earth's surface. At the present time, the relationship between magnetic storms and substorms is a matter of considerable debate. Questions as to whether a magnetic storm is simply a collection of substorms; if there is an element unique to the storm process, and if there are differences between a substorm that occurs during a magnetic storm and one that occurs in isolation during a quiet period, remain unresolved.

Also, our understanding of the processes inherent in the input to, and decay of, energy in the terrestrial environment during substorm events is very incomplete (Tsurutani et al., 1997; Baker et al., 1997; Kamide et al., 1998a, 1998b and references therein). It has been suggested that energy release is initiated by a trigger event in the incident solar wind or, alternatively, that it is due to an inherent magnetospheric instability for which no trigger is required. Some argue that both processes play a role. Related questions concern the location in the tail of magnetic re-connection processes and the timing of such events with respect to other disturbance signatures. From among several competing models, two have emerged as leading contenders with respect to the site of substorm initiation, namely the Tail Current Disruption Model/TCD (Lui, 1991) and the Near Earth Neutral line/NENL model (e.g. Baker et al., 1996, also Baker, 2003 and references therein).

An historical account of how early paradigms concerning ring current sources (as well as the process of storm-time 
ring current growth) have come, as a result of studies of data recorded in space, to be superseded, is contained in Daglis (2001). At the present time, the immediate particle sources of the ring current are considered to be the plasma sheet and the ionosphere, thereby implying that the primary sources concerned are provided, respectively, by the solar wind and by the Earth's upper atmosphere. The relative contribution of these two sources is not presently established. It is, however, recognised that the contribution of the ionosphere to the ring current, which mainly comprises $\mathrm{O}^{+}$ions (Young et al., 1982; Hamilton et al., 1988), increases with storm magnitude. Since ring current enhancement and decay are determined in large part by the motions of terrestrial $\mathrm{O}^{+}$ions during the largest storms (Burch, 2003 and contained references), it was surmised by Daglis (1997) and by Moore et al. (2001), that a pre-requisite for the development of a large ring current is, significant, ionospheric outflow. Observations by Mitchell et al. (2003) showed that, during geomagnetic storms when magnetospheric convection is enhanced, bursts of neutral oxygen atoms with durations of the order of $30^{m}$ occur in the range $52-180 \mathrm{keV}$. Related simulations and observations indicated that $\mathrm{O}^{+}$outflow mechanisms would have been insufficient to energize ionospheric oxygen up to energies of several hundred keV. A non-adiabatic mechanism proposed by Delcourt (2002) was, in these circumstances, suggested to provide a possible process. It is not, however, currently understood what effect ionospheric plasma has on substorm evolution, or on the onset and evolution of related substorms and storms (Ohtani et al., 2000).

Studies by Wygant et al. (1998) and by Fok et al. (2001) indicate that pressure plays a major role in the morphology, dynamics and strength of the electric field of the inner magnetosphere, because of the closure in the ionosphere of the Region 2 current system. Increased understanding of the global pressure in the magnetosphere is, thus, germane to obtaining an increased understanding of the coupling between the inner magnetosphere and the ionosphere.

Also, knowledge concerning the development of pressure inside the magnetosphere during magnetic storms is a vital element in understanding the role played by stretching of the Earth's magnetic field lines at storm-times (Tsyganenko et al., 2003). In this connection, the energization and loss of radiation belt protons and electrons is believed to be intimately related to the changing topology of the magnetic field in the inner magnetosphere during magnetic storms. Results reported by Brandt et al. (2002a) suggest that, during the main phase of such events, ions (unexpectedly) flow into the post-midnight sector in consequence of the presence of skewed electric fields in the inner magnetosphere. The exit, thereafter, of these ions through the dusk (or afternoon) magnetopause, can have implications for the time that substorm injected particles remain within the magnetosphere. It was shown by Fok et al. (2003) that the enhanced ion flux mentioned above can be explained in terms of twisted drift paths predicted to be present near dawn by a self consistent, MI coupling ring current model CRCM (Comprehensive Ring Current Model) published earlier by Fok et al. (2001).
Variations in the density, temperature and composition of the plasma sheet, saturation of the polar cap potential drop (and probably also of the cross-tail potential drop); modifications to the imposed convection potential in the inner magnetosphere due to ring current shielding effects; the presence of a pre-existing ring current population; storm/substorm coupling and storm convection, with and without accompanying substorm activity, have all been listed by Kozyra and Liemohn (2003) as factors having an impact on ring current formation and decay. While this implies that the situation is inherently very complex, it can at least be inferred that the geo-effectiveness of a particular solar wind driver cannot be predicted on the basis of the characteristics of that driver alone, but must involve, in addition, key aspects of the dynamically changing geospace environment itself.

Meanwhile, recognition that the ring current during the main phase of magnetic storms is asymmetric and driven mainly by plasma convection in the magnetosphere, leaves many related questions unanswered, including, whether or not the inner magnetosphere is populated mainly by convective processes or through impulsive injections driven by substorm-associated inductive electric fields (Sharma et al., 2004). The processes responsible for the injection, transport, acceleration and loss of ring current particles are far from being understood and the problem of distinguishing between competing theories continues to be widely discussed within the community (e.g. Friedel et al., 2002; Burch et al., 2005; Pulkkinen et al., 2005).

Energetic Neutral Atom imaging (see below), because of its global perspective and power to separate temporal and spatial variability in the Earth's close environment, has a particular potential to support studies of the complexities of ring current and magnetic storm/substorm dynamics.

\section{Energetic neutral atom production/imaging/analysis}

Energetic Neutral Atoms (ENAs) are produced in the Earth's magnetosphere when energetic magnetospheric ions undergo charge exchange collisions with the population of thermal, neutral, hydrogen atoms that make up the geo-corona. In such an interaction, an energetic ion can acquire the electron of an hydrogen atom. Hydrogen is the main geocoronal constituent at high altitudes, but helium and oxygen are also present. While helium can, in general, be neglected in the pertaining charge-exchange process, oxygen, due to its low cross section, can play a role in ENA generation (see Fig. 1 which provides an illustration of the charge exchange process for oxygen). At low ion energies, the cross sections for charge exchange (electron pickup) are in the relatively high, $10-15 \mathrm{~cm}^{2}$ range (McEntire and Mitchell, 1989). For a review of the main interactions in the upper atmosphere, see De Michelis and Orsini (1997). The $\mathrm{H}^{+}$cross section begins to fall off significantly for proton energies exceeding $10 \mathrm{keV}$ and, thereafter, drops off steeply above $550 \mathrm{keV}$. This has the consequence that ENA hydrogen spectra are concentrated below $200 \mathrm{keV}$. Similarly, the $\mathrm{O}^{+}$cross section decreases below 


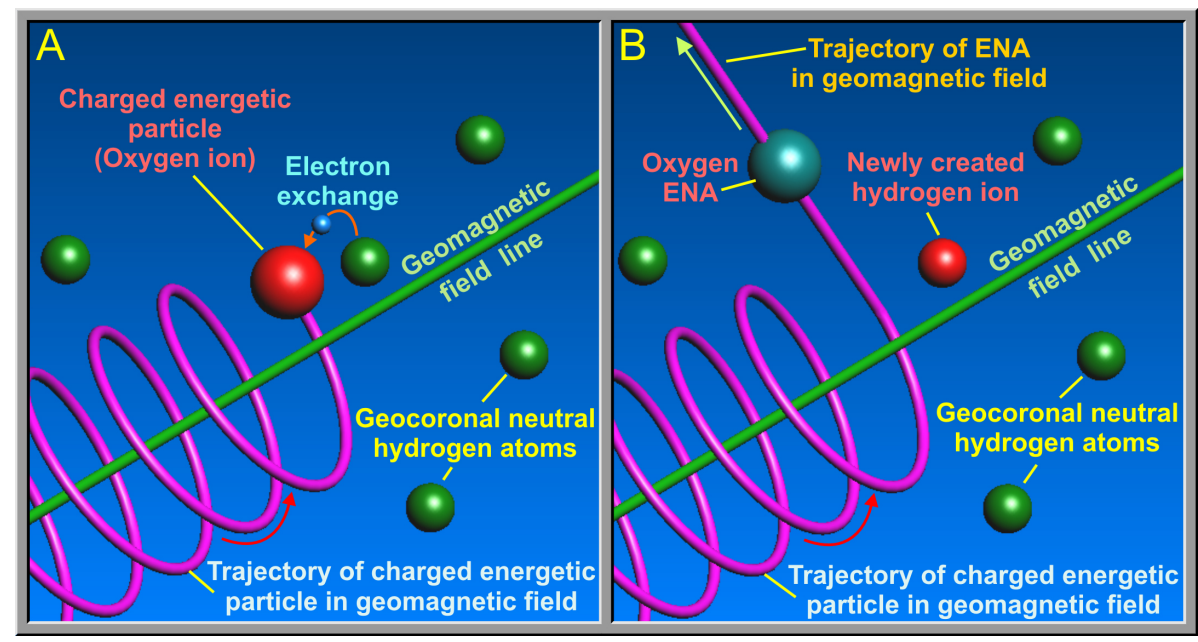

Fig. 1. An energetic plasma immersed in a neutral gas background emits energetic neutral atoms (ENAs), generated due to the charge exchange process. The example provided is for an oxygen ion, but the charge exchange interaction is valid for any singly charged ion.

$200 \mathrm{keV}$ and drops off steeply below $1 \mathrm{MeV}$. Viewed overall, the energy spectra of different species are very steep at high energies and have a cut-off at about $1 \mathrm{MeV}$ (Spjeldvik and Rothwell, 1985).

A few electron volts of energy are lost during a typical resonant charge exchange collision. Thereafter, the ENAs produced propagate from their site of creation, along straightline (photon-like) trajectories at $\mathrm{keV}$ energies, unimpeded by the Earth's electric and magnetic fields, and negligibly affected by gravitational forces.

Such straight-line trajectories suggest that ENA emissions may be utilised to form an image of their parent, charge exchanging, populations. This possibility has been successfully realised in practice over the past several decades (see the brief historical overview contained in McKenna-Lawlor et al., 2005, and references therein). By means of this methodology, neutral atom images of plasma structures in geospace can be formed from integrated emissions made along the lines of sight, linking the location of ENA production to the vantage point of a particular imager flown aboard a spacecraft. By suitably composing these ENA images into ENA movies, it is possible to study the dynamic responses of the ring current to changes in interplanetary conditions.

A feature of ENAs is that they are emitted anisotropically due to the inherent pitch-angle distributions (PADs) of their parent ions. The data can, accordingly, be utilised (see below), to reconstruct the global, equatorial, ion distributions. In the case of hydrogen and oxygen ENAs (the dominant local products of $\mathrm{H}^{+}$and $\mathrm{O}^{+}$charge exchange), the relevant energy distributions span a range between a few $\mathrm{eV}$ and several hundred $\mathrm{keV}$.

A number of ways to retrieve the parent ion distributions have been developed, of which the most frequently used are forward modelling and constrained linear inversion (e.g. Roelof, 1987; Brandt et al., 2002b; Roelof and Skinner, 2000; Perez et al., 2000, 2001; Demajistre et al., 2004; Vallat et al., 2004). Since inversion methods use smoothing constraints, it is important to keep in mind that, even though the results obtained may appear to be reasonable, they must be carefully validated using in-situ data. Further, if the instrumental response is not properly taken into account, inherent errors can corrupt the result obtained.

\subsection{Low altitude/high altitude ENA observations}

High-altitude ENA measurements made aboard the POLAR spacecraft (orbit; $\sim 1100 \times 57000 \mathrm{~km}$ ) and aboard IMAGE (orbit; $\sim 1000 \times 46000 \mathrm{~km}$ ), emphasise the value of being able to simultaneously image the whole ring current during a magnetic storm. Such data permit direct correlations to be made between globally integrated ENA images and the total energy of the ring current (Brandt et al., 2003; Jorgensen et al., 1997), while in addition, allowing the storm-time injection process to be visually tracked (Brandt et al., 2002b). Azimuthal asymmetry can be seen to evolve during a magnetic storm, reflecting the cumulative effects of ion drifts and the establishment and decay of the partial ring current (see, for example, Blake et al., 1995; Burch, 2003; Brandt et al., 2002a; Kozyra and Liemohn, 2003; Pollock et al., 2003). The drift of injected ions was first imaged by POLAR CEPAD/IPS, (Henderson et al., 2000). (See also the comparison of storm versus substorm injections contained in Reeves and Henderson, 2001; Reeves et al., 2004).

At low altitudes, the density of the upper atmosphere and exosphere increases and the composition changes from a hydrogen dominated to an oxygen dominated environment. Data recorded by the PIPPI instrument aboard the Astrid satellite, which was launched into a 1000-km circular orbit with $83^{\circ}$ inclination, showed ENA emissions in the energy range $13-52 \mathrm{keV}$ coming from auroral/subauroral L shells during a moderate storm (Brandt et al., 2001). The peak ENA flux correlated well with a decrease in the pertaining Dst index. It was suggested that the most intense ENA emissions 
were produced by precipitating, and nearly mirroring, ions in the dusk region moving along auroral/subauroral field lines and charge exchanging with the oxygen exosphere near the exobase (300-400 km) (Barabash et al., 1997; Brandt et al., 1999, 2001).

Based on a consideration of ENA imaging from both high and low-altitude spacecraft, Roelof (1997a, b), derived an analytical expression for the ENA production function close to the exobase, while employing the approximation of single charge exchange and ionisation collisions between energetic ions and exobase neutrals at polar cap locations and taking into account both thick and thin optical depths.

An advantage of low altitude imaging is that the ENA flux is two orders of magnitude higher than in the case of, typically sampled, high-altitude ENA emissions. This allows the employment at perigee of short integration times $(\sim 16 \mathrm{~s})$, whereas ENA images of the ring current from apogee require an approximately 10-min integration time, using today's instrumentation. A disadvantage is the small solid angle subtended by the low-altitude ENA emissions which emanate from a very narrow layer (maximum ENA production at $\sim 350 \mathrm{~km}$ from a layer $<100 \mathrm{~km}$ thick). In Sect. 6, ENA images obtained by the NUADU instrument aboard TC-2 during a south polar pass (at $\sim 600 \mathrm{~km}$ ) are presented.

\section{The NUADU instrument}

The potential of ENA imaging to provide valuable insights into dynamic magnetospheric processes, prompted the development of a NeUtral Atom Detection Unit (NUADU) for China's TC-2 spacecraft (measurement range 45$>158 \mathrm{keV}$ ).

\subsection{The NUADU sensor head}

The NUADU instrument is designed to remotely sense $4 \pi$ distributions of energetic neutral atoms through employing 16 detectors and exploiting spacecraft spin. Figure 2 presents a virtual model of the NUADU sensor head. Several of the sensors (Passivated Ion-implanted Silicon Detectors/PIPS), which are mounted at four different heights, are visible in this representation. In the foreground, the entrance apertures, each of which is located $228 \mathrm{~mm}$ away from its corresponding sensor, can also be seen. These apertures are covered by a fine shielding mesh (not shown), which is maintained at a voltage of $-20 \mathrm{~V}$.

Figure 3 (left) provides a schematic view of the internal structure of a representative PIPS detector. Electrical contact to the detector chip is provided by soft, electrically conducting rings, and the chip is pressed between two such rings. The contact area on the entrance window side is limited by an aluminium ring which is deposited directly onto the silicon surface. The contacting rubber ring must be precisely aligned with the aluminium contact ring, since any misplacement can cause a large increase in leakage current and noise. Anomalous noise typically sets in when low temperature regimes

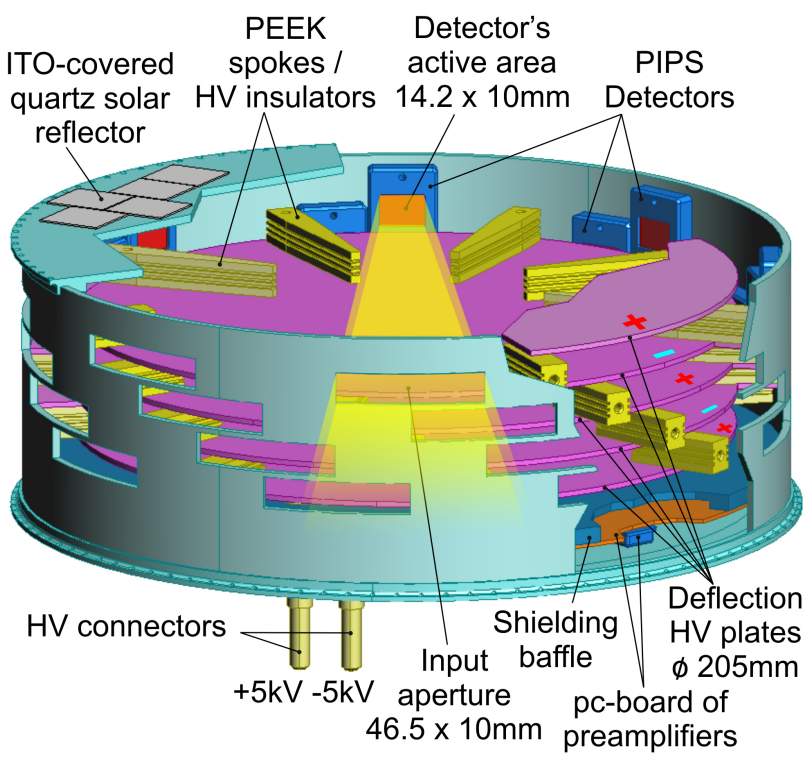

Fig. 2. Exploded 3-D-view of the NUADU Sensor Head.

are experienced, due to the associated contraction/dilation effects that lead to contact problems. Against this background, particular care was taken to ensure that the detectors selected for NUADU would be reliably mounted.

Each of the detectors has a thickness of $300 \mu \mathrm{m}$ and they are all operated at full depletion. A metalization layer $(150 \mathrm{~nm}$ of $\mathrm{Al})$ is deposited on each detector to render it impervious to both UV and X-radiation. Each has a rectangular active area of $14.2 \times 10 \mathrm{~mm}$ and an input aperture of $46.5 \times 10 \mathrm{~mm}$ (located at the opposite side of the sensor head at a distance away of $228 \mathrm{~mm}$ ). The detectors have, individually, equal fields of view $\left(11.5^{\circ} \times 2.5^{\circ}\right.$ fwhm $)$, regularly distributed over an $180^{\circ}$ angle in the elevation plane. Figure 4 illustrates the pointing angle and angular response of each of the sixteen detectors in the elevation plane (the spacecraft spin axis points towards the north ecliptic pole).

The spacecraft spin (4s) allows the azimuthal plane to be divided into 128 equal sectors through counting pulses provided by the spacecraft "Spin Segment Clock". The full $4 \pi$ angle is, accordingly, divided, into $16 \times 128=2048$ pixels and, at the 4-s spacecraft spin period, the integration time of each pixel is $31.25 \mathrm{~ms}$. NUADU can provide a full $4 \pi$ image on the completion of each spacecraft spin in synchronisation with the Spin Reference Pulse provided by the spacecraft. It is possible to integrate $(\mathrm{N})$ spins on board over the range $\mathrm{N}=1-32$. Further integration of the images can be performed on the ground to improve the count statistics. Due to telemetry constraints, the instrument normally operates at $\mathrm{N}=4$.

\subsection{The deflection system}

An electrostatic, high voltage $( \pm 5 \mathrm{kV})$ deflection system is installed inside the Sensor Head to sweep away charged particles with energies $<300 \mathrm{keV}$ from the detectors. This system provides a field intensity of $10 \mathrm{kV} / \mathrm{cm}$ inside the 

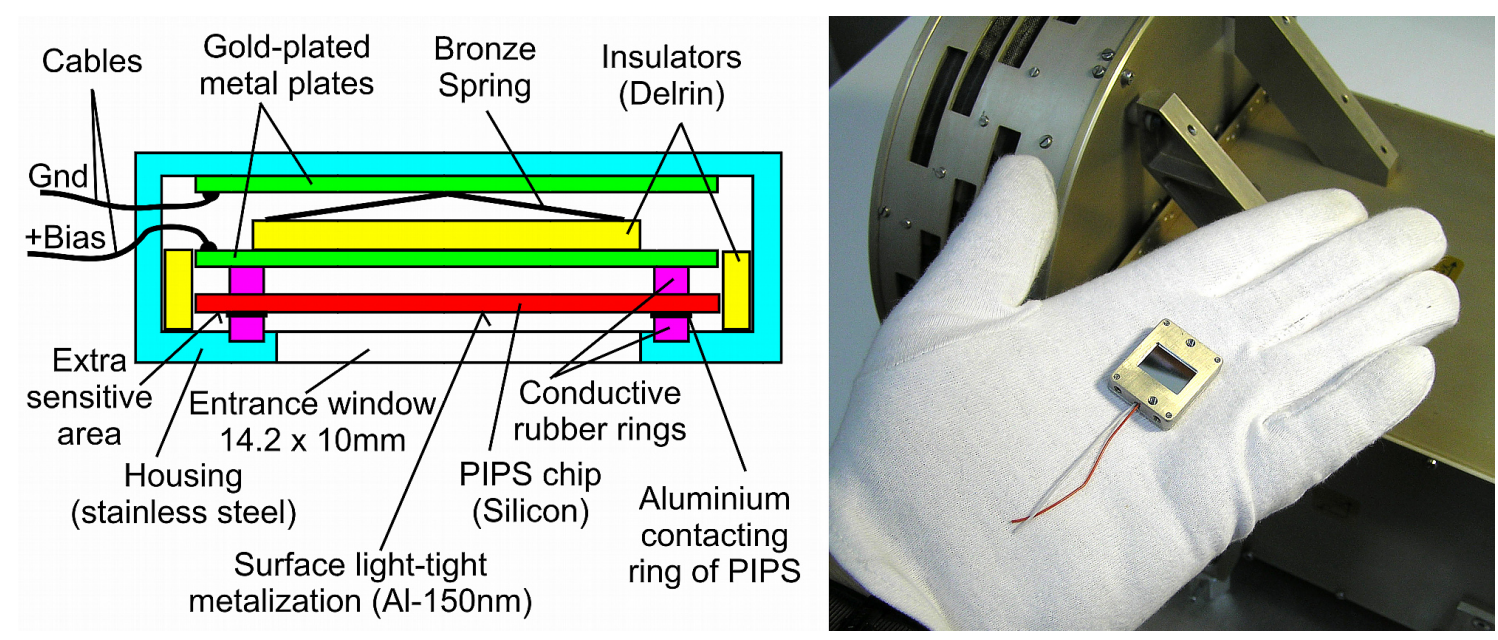

Fig. 3. (Left) sketch showing the internal structure of a PIPS detector; (right) view indicating the physical size of such a detector.

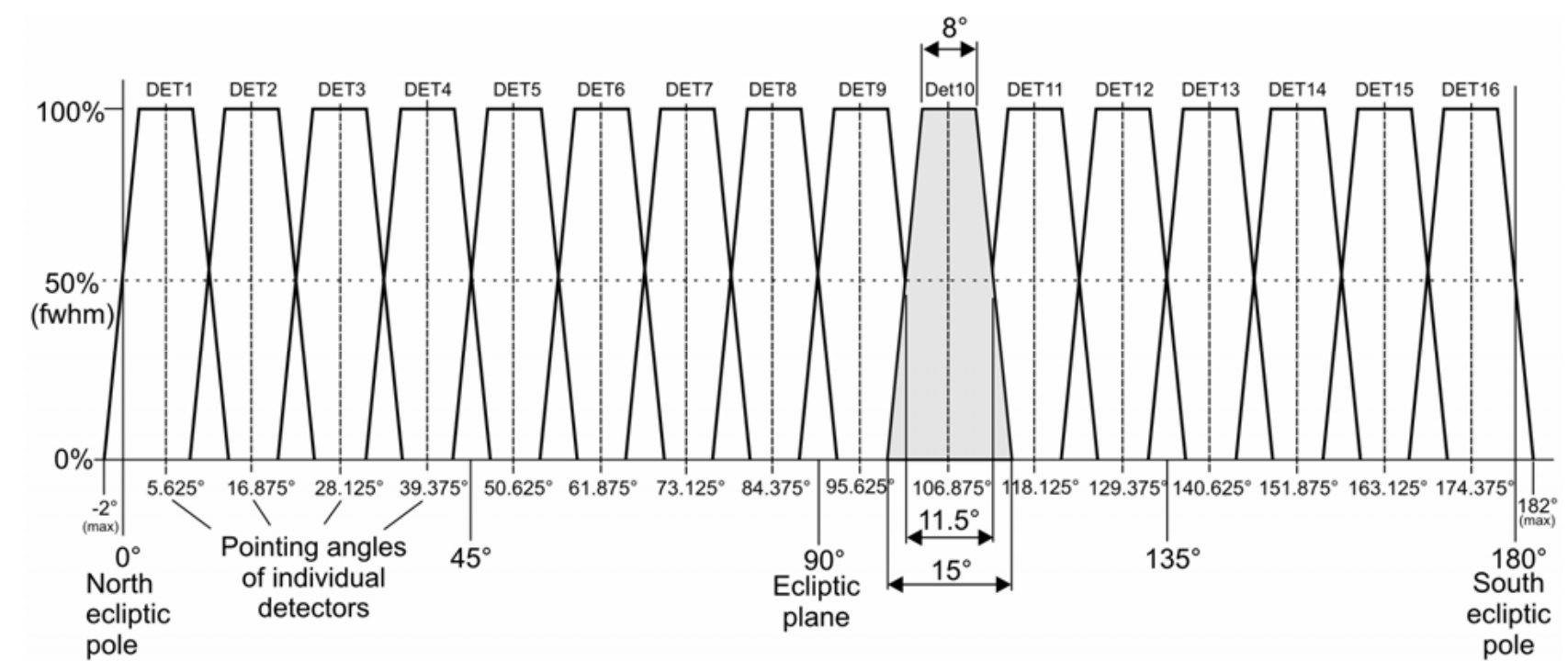

Fig. 4. Pointing angles and angular response of the 16 detectors in the elevation plane (the spacecraft spin axis points to the north ecliptic pole).

deflection gap. Figure 5 shows the relative positions of four of the associated deflection plates, which were individually manufactured from copper epoxy fibre-glass (thickness $1.6 \mathrm{~mm}$ ), and maintained mechanically separated by means of a set of insulating spokes made from PEEK (Poly-EtherEther-Ketone). The surface of each plate was treated with black copper sulphide; the edges are rounded and plated with polished gold to inhibit electrostatic discharges on orbit.

A dedicated HV unit supported by a $+24 \mathrm{~V}$ secondary power distribution, energises the deflection system and delivers regulated, symmetrical, bipolar voltages in the range 0 to $\pm 5 \mathrm{kV}$. The output bipolar voltages are monitored by the NUADU Data Processing Unit (DPU) with 8-bit resolution. Another control from the DPU provides for direct, alternate, ON/OFF switching of the high-voltage using optocouplers. The resulting Toggle Mode allows contributions to the measured fluxes of charged particles up to the cut-off limit (Sect. 4.3) to be evaluated.

\subsection{The deflector cut-off energy}

Ray tracing was performed to determine the deflector cutoff energy, the angular response of a representative sector and the geometric factor for a single detector (see below). The simulation program utilised (SIMION 3-D 7.0 ion optics simulation software), which was primarily designed to model the electrostatic (or magnetic) fields produced between representative electrodes, allowed ions to be flown within a potential array tailored to the present application. To find the potential of points between the electrodes concerned, the SIMION program first solved the Laplace equation (for which the electrodes provided the boundary conditions). An iteration method was then employed to find the potential at a 


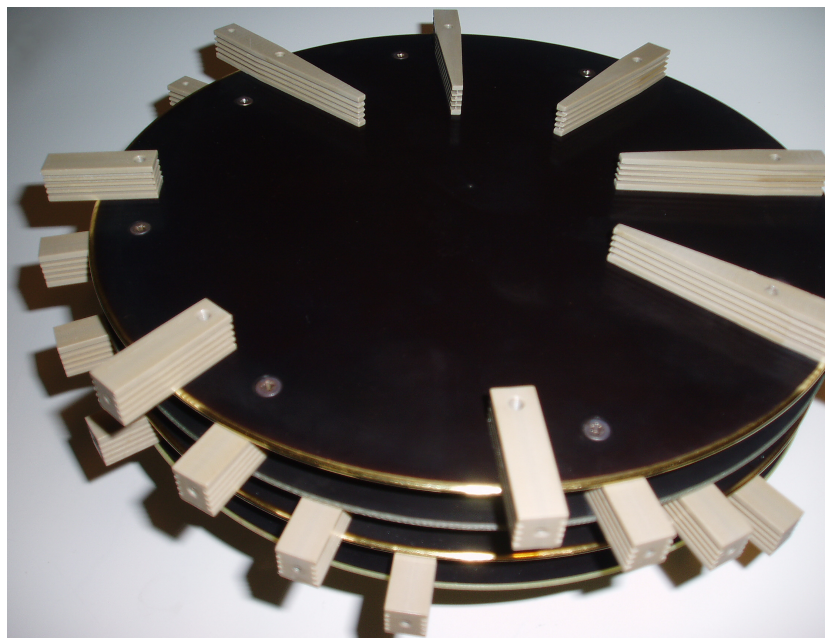

Fig. 5. Part of the HV deflection/collimation system which consists of circular plates and supporting PEEK insulators/spokes (the top plate is removed).

particular point through determining the values presented by its nearest neighbours.

The model thus created, reflected the conditions provided by a typical NUADU sensor, and protons and electrons could be flown through this system in sets, characterised by a specific starting energy. Equally spaced (every $4.6 \times 2.0 \mathrm{~mm}$ ) starting points that completely covered the aperture of a representative detector were utilised and, at each starting point, ions were flown from azimuth $(\alpha)$ angles of $-30^{\circ}$ to $+30^{\circ}$ and elevation $(\beta)$ angles of $-10^{\circ}$ to $+10^{\circ}$, where $\Delta \alpha$ and $\Delta \beta$ were each $1^{\circ}$. A total of 66 starting points allowed 84546 particles to be flown at each energy setting in a range from $1 \mathrm{keV}$ to $1 \mathrm{MeV}$. A user program to count the number of ions that actually hit the sensitive area of the detector $\left(\mathrm{N}_{\text {hit }}\right)$ was then developed to evaluate (Sect. 4.3.2) the geometric factor.

\subsubsection{Results (deflector cut-off energy)}

The cut-off energy of the deflector plates determines the high-energy limit of neutral particles for the NUADU instrument. This cut-off is defined as the energy where $N_{\text {hit }} / N=0.01 . N_{\text {hit }}$ is the number of ions that hit the detector with the deflection voltage $\mathrm{ON}$, and $N$ is the number of ions that hit the detector at $0 \mathrm{~V}$.

Figure 6 displays the simulated percentage of protons of different energies that reached a representative detector. This plot shows that the simulated cut-off energy for the NUADU deflection system for protons at the (maximum) deflection voltage of $10 \mathrm{kV}$ was $320 \mathrm{kV}$.

\subsubsection{The geometric factor}

The geometric factor for a two element telescope can be found from

$G=\int_{\Omega} d \omega A(\omega)$, which is approximated by $G \leq \frac{S_{1} S_{2}}{l^{2}}$,

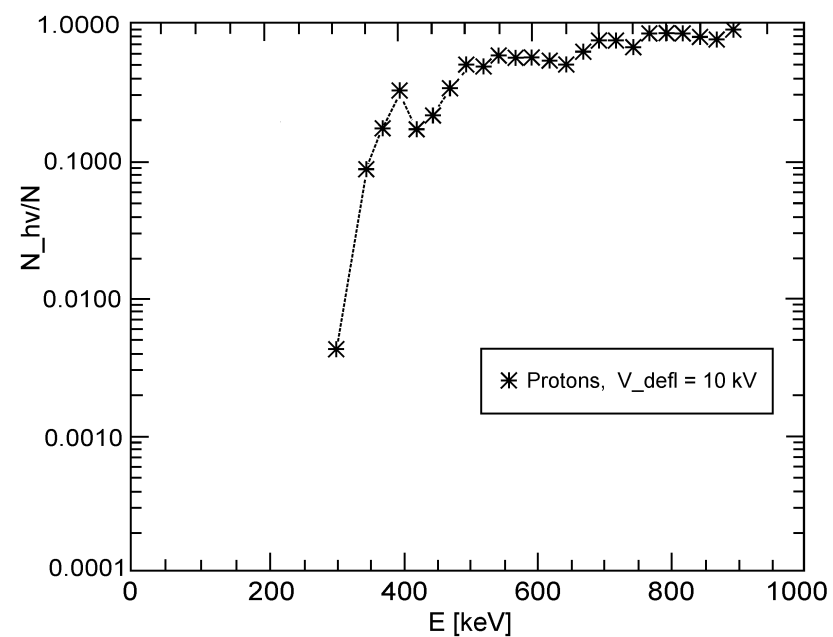

Fig. 6. Plot showing the simulated percentage of protons of different energies that reach a representative detector at nominal deflector HV settings of $10 \mathrm{kV}$.

where $S_{1}$ is the aperture area; $S_{2}$ is the detector area and $l$ is the distance between them. This gives an approximate geometric factor for NUADU of $G_{\text {approx. }}=1.246 \times 10^{-2} \mathrm{sr} \mathrm{cm}^{2}$. To calculate an exact value $\left(G_{\text {true }}\right)$ for the geometric factor, however, the integral should be evaluated and this resulted in the value $G_{\text {true }}=1.227 \times 10^{-2} \mathrm{sr} \mathrm{cm}^{2}$ per sector.

A further estimation of the geometric factor based on the results of simulation can be found using the expression

$G_{\text {sim }}=\Delta A \Delta \alpha \Delta \beta \cdot N_{\text {hit }}$,

where $\Delta A$ is the aperture area enclosed by four neighbouring starting points; $\Delta \alpha$ and $\Delta \beta$ are the azimuth and elevation angle increments between flown ions and $N_{\text {hit }}$ is the number of ions that hit the detector. This yielded a geometric factor of $G_{\mathrm{sim}}=1.398 \cdot 10^{-2} \mathrm{sr} \cdot \mathrm{cm}^{2}$. Given that modifications were made to the simulation program to adapt it to the NUADU application, this is satisfactorily close to the analytical approximation, as well as to the analytically exact value.

The very large geometric factor of NUADU is an important feature of the instrument (note that, since a mechanical collimator is used, the pixel size does not depend on particle energy and mass, as is the case in TOF designs). For comparison, the geometric factor of the HENA instrument on IMAGE is $0.0027 \mathrm{~cm}^{2}$ sr per $3^{\circ} \times 3^{\circ}$ pixel.

\subsection{Energy calibration of NUADU}

The NUADU Sensor Head was calibrated at the Manne Siegbahn Laboratory at Stockholm University, Sweden, using neutral atom beams generated at different energies (see below) within a 30-m diameter ring accelerator. The objective was to decide, based on the responses of the detectors, on appropriate threshold values for the four discriminators that determine the energy channels of NUADU (see also Sect. 4.7).

The species and energies of the energetic neutral atom beams employed during the calibration are presented in 

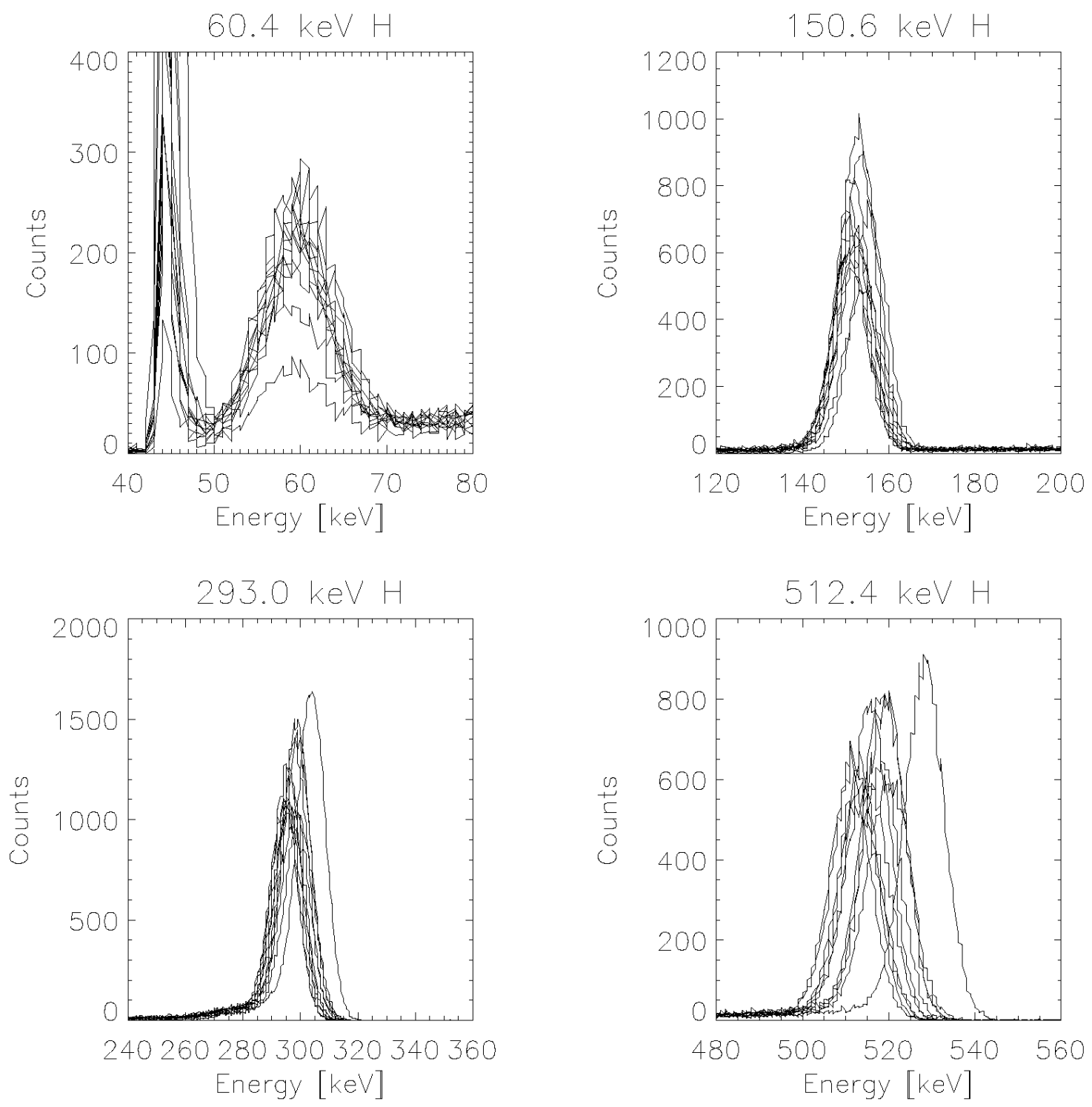

Fig. 7. Responses of all the detectors to hydrogen neutral atom beams of different energies (60.4, 150.6, 293.0 and 512.4 keV, respectively).

Table 1. Energies of $\mathrm{H}$ and $\mathrm{O}$ neutral atoms used in the NUADU calibration.

\begin{tabular}{cccccc}
\hline Species & \multicolumn{5}{c}{ Energies [keV] } \\
\hline $\mathrm{H}$ & - & 60.4 & 150.6 & 293.0 & 512.4 \\
$\mathrm{O}$ & 149.8 & 229.9 & 301.1 & 393.5 & 501.8 \\
\hline
\end{tabular}

Table 1. During the measurements, the responses of all 16 detectors to the various beams were determined (see Figs. 7 and 8), and the corresponding output pulse heights from the NUADU amplifiers were recorded using a multi-channel analyser (for details, see McKenna-Lawlor et al., 2004). For $150 \mathrm{keV}$ Hydrogen, the energy resolution at FWHM was, thereby, found to be $8 \%$. For $300 \mathrm{keV}$ Oxygen, the corresponding resolution was $28 \%$.
It was observed that Detector 13 showed slightly elevated pulses at relatively high energies of the hydrogen beam. This could indicate that it has a thinner than average metalization layer. However, its performance was deemed to be acceptable and no problem has been experienced with regard to D-13 on-orbit. It is noted that the width of the calibration beams available at the accelerator did not allow the dead layer/metalization layer of the individual detectors to be determined and, thus, the values given by the manufacturer are utilised when determining energy spectra.

It was found from plots showing how the voltage pulse amplitudes are related to particle energy that, if $E$ is in $\mathrm{keV}$ and $V$ is in volts, then for $\mathrm{H}$

$V=\left(0.00496682 \times E_{H}\right)-0.156747$

and for $\mathrm{O}$

$V=\left(0.00330185 \times E_{O}\right)-0.364899$. 

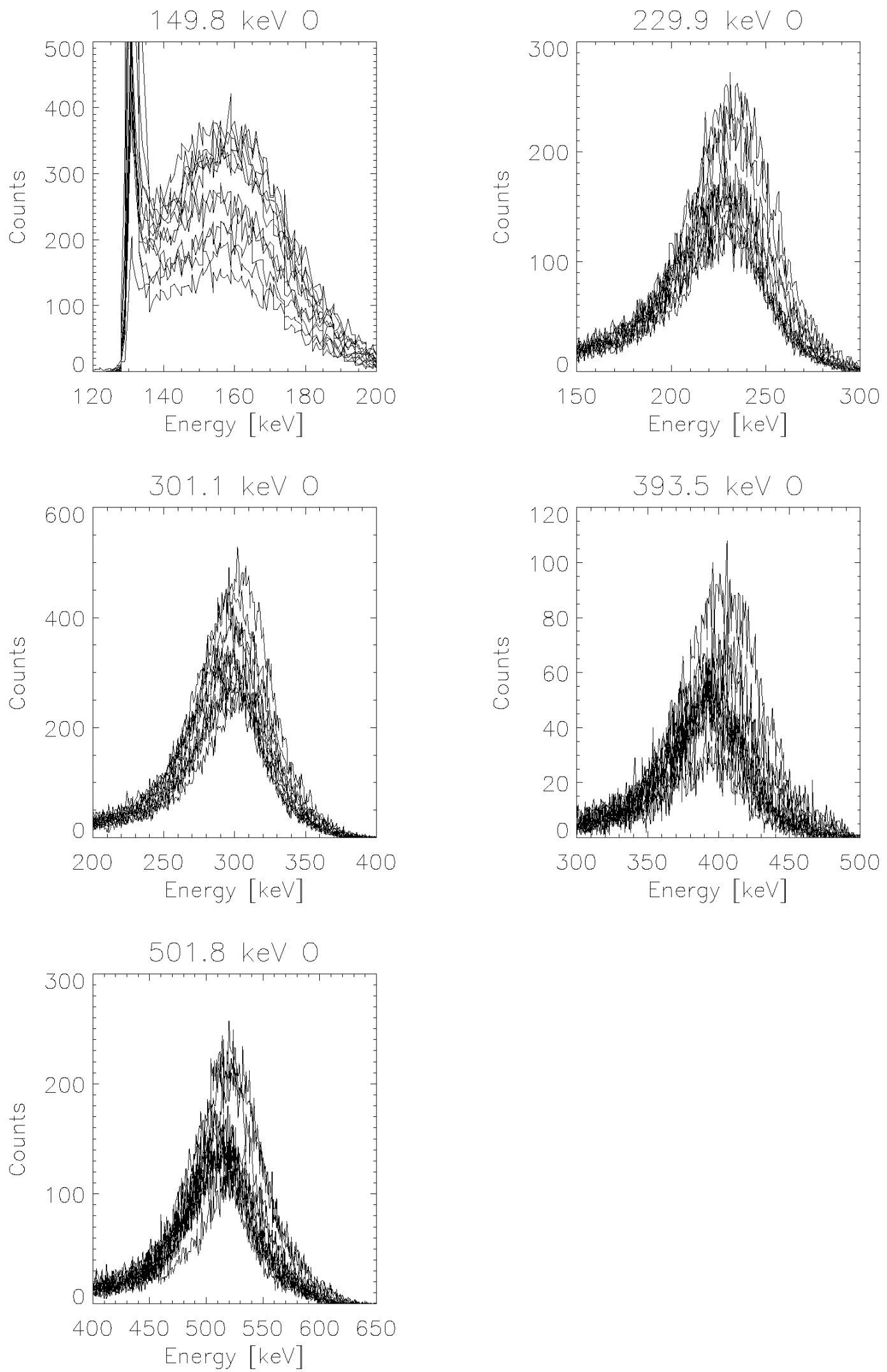

Fig. 8. Responses of all the detectors to oxygen neutral atom beams of different energies $(149.8,229.9,301.1,393.5$ and $501.8 \mathrm{keV}$, respectively). 


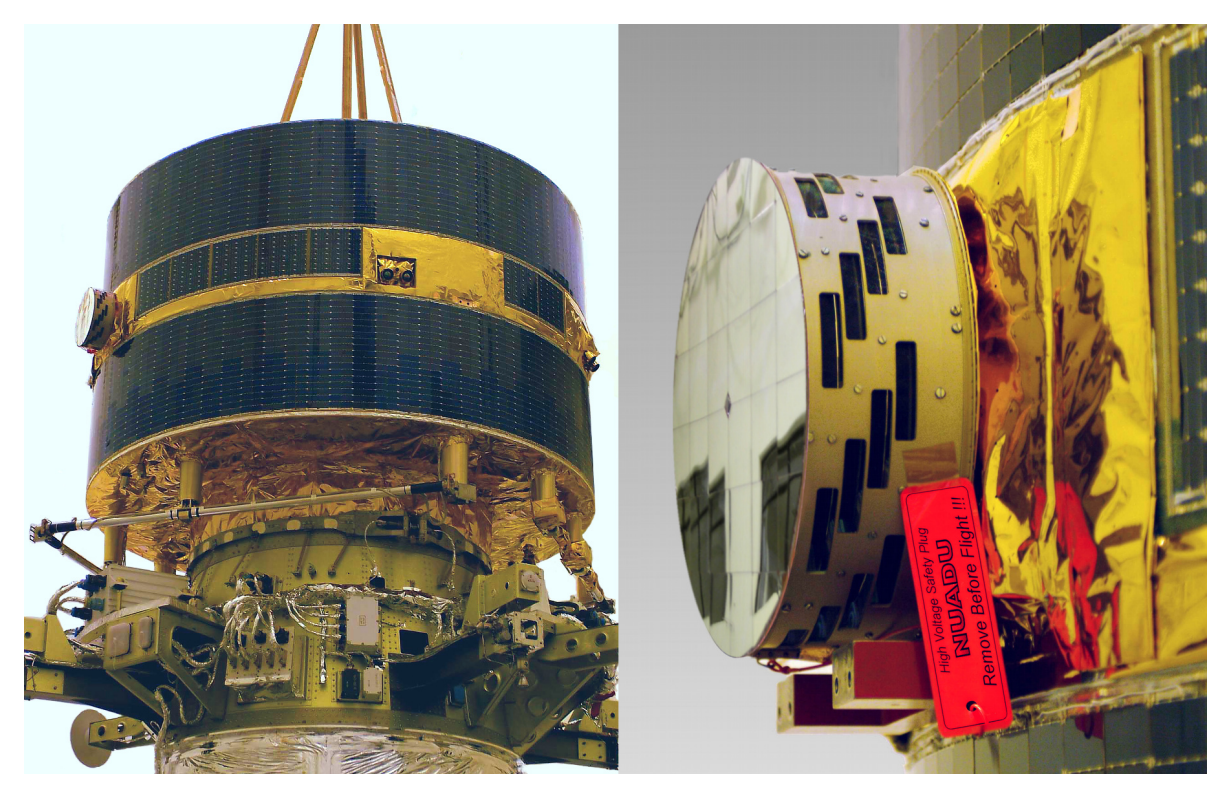

Fig. 9. (Left) view of the TC-2 spacecraft before launch, showing the position of NUADU on board; (right) close up view of NUADU, showing the input apertures and the quartz Optical Solar Reflectors (OSRs) mounted on the outer surface of the Sensor Head.

Setting the discriminator thresholds based on the calibration measurements involved taking into account a number of factors including:

- Simulated energy spectra for quiet and disturbed interplanetary conditions, based on the known dependency of the charge exchange cross section on energy;

- The NUADU deflector cut-off energy;

- Energy resolution/straggling in the metalization and dead layers;

- The possibility of indirect mass identification.

In addition, the possibility to perform stereo measurements during the TC-2 mission between NUADU and the HENA instrument flown on the IMAGE spacecraft (see Sect. 5.1), caused special consideration to be given to providing an adequate overlap between the energy ranges covered by the NUADU and HENA/IMAGE instruments.

Table 2 presents the energy bands/discriminator thresholds selected for NUADU. Of these, the setting of Threshold 1 can be varied on-orbit by tele-command, so that it can be set above the prevailing noise level. The background experienced during commissioning, inspired the present setting of this threshold at $45 \mathrm{keV}$. It is noted for comparison that the complementary energy levels of IMAGE/HENA are E4: 3950 keV, E5: 50-60 keV, E6: 60-81 keV, E7: 81-119 keV, E8: 119-198 and E9: >198 keV.

\subsection{Thermal considerations}

A requirement for NUADU was a design that would allow the detectors to operate at a temperature conducive to a noise free performance $\left(\leq-10^{\circ} \mathrm{C}\right)$ on-orbit. Since the Sensor Head (SH) protrudes outside the skin of the spacecraft platform, to provide a clear field of view for each of its 16 PIPS (see Fig. 9, left), the Sensor Head could potentially run either too "hot" or too "cold" under different foreseen conditions (as simulated by the NUADU thermal model). It was thus required that the outer surface of the Sensor Head should be covered by quartz Optical Solar Reflectors/OSRs $(\alpha=0.078$ and $\varepsilon=0.78$ ), to allow a balance temperature to be achieved in space that would be conducive to noise free operation. Figure 9 (right) provides a view of the OSRs on the outer surface of the Sensor Head.

Also, a 5-Watt heater was installed inside the Sensor Head to ensure that the instrument would not run so cold during long $\left(>1^{h}\right)$ eclipses that the rubber rings would harden and develop unreliable electrical contacts. The power control for this heater is maintained by the spacecraft system, based on temperature sensing provided by an externally mounted thermistor. The threshold (ON/OFF) settings for this heater were set, following on-orbit thermal commissioning, at $-25^{\circ} \mathrm{C} /-20^{\circ} \mathrm{C}$. The balance temperature, under normal operation, is approximately $-10^{\circ} \mathrm{C}$.

The NUADU Electronic Box (Sect. 4.6), which is mounted on the experimenters platform, is thermally enclosed inside the spacecraft under Multi-Layer-Insulation (MLI). Since its power dissipation is rather low $(4.7 \mathrm{~W})$, this unit, which is thermally de-coupled from the Sensor Head, "follows" the platform temperature, which is itself controlled by the spacecraft, within a range that ensures a safe operational margin for the electronics under both nominal and eclipse conditions.

\subsection{The electronic boards and box}

The electronics serving the individual detectors (namely the charge sensitive pre-amplifiers, pulse operational amplifiers, discriminators and event counters) are mounted on a 
Table 2. Energy bands for NUADU.

\begin{tabular}{ccccccc}
\hline Energy channel & $\mathrm{H}[\mathrm{keV}]$ & $\mathrm{O}[\mathrm{keV}]$ & $\Delta \mathrm{E}_{H}[\mathrm{keV}]$ & $\Delta \mathrm{E}_{O}[\mathrm{keV}]$ & $\Delta \mathrm{E}_{H} / \mathrm{E}_{H}$ & $\Delta \mathrm{E}_{O} / \mathrm{E}_{O}$ \\
\hline E1: TH1-TH2 & $* 46-50$ & $* 132-139$ & 4 & 7 & $8 \%$ & $5 \%$ \\
E2: TH2-TH3 & $50-81$ & $139-185$ & 31 & 46 & $47 \%$ & $28 \%$ \\
E3: TH3-TH4 & $81-158$ & $185-300$ & 77 & 115 & $64 \%$ & $47 \%$ \\
\hline
\end{tabular}

* TH1 is adjustable by telecommand.

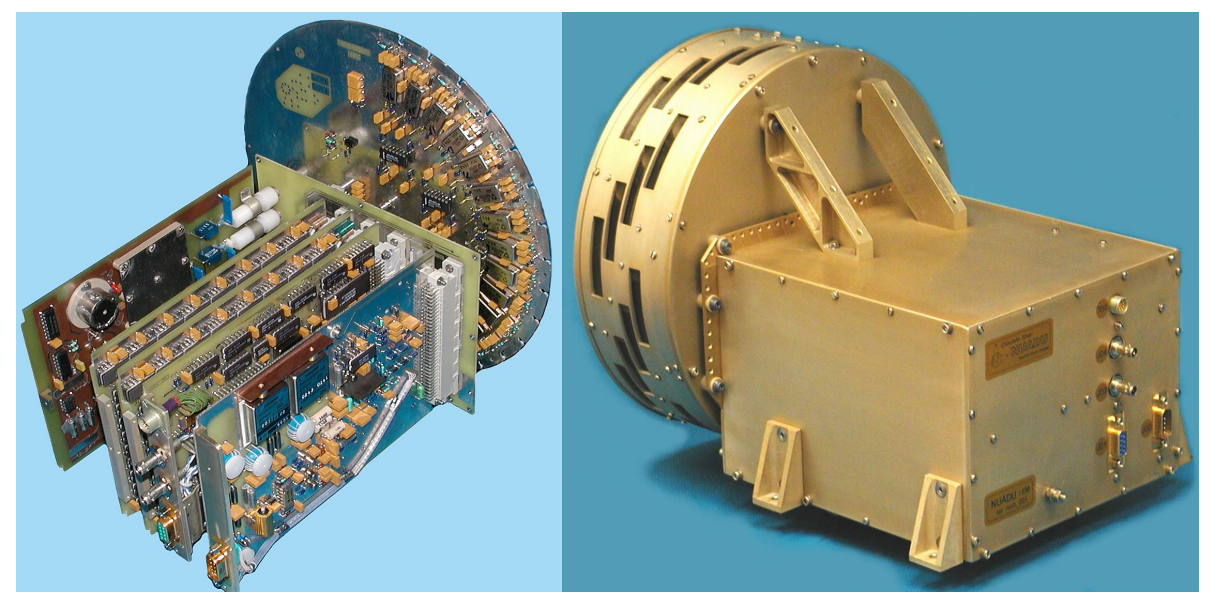

Fig. 10. (left) view of the electronic boards that are mounted inside the electronic box; (right) external view of the electronic box.

board called FRONT, situated in the Sensor Head (see also Sect. 4.7).

Figure 10 (left) shows the 6 other electronic boards utilized (i.e. a "mother board"; a high voltage board; two discriminator counter boards; a data processing unit board and a power distribution board). The electronics box (Fig. 10, right) which houses the digital electronics, is fixed to the spacecraft platform by means of four rugged lugs fitted with titanium screws. The box structure functions, in addition, to provide mechanical support for the Sensor Head. It is manufactured from space-qualified aluminium alloy, to which an electrically conducting treatment (IRIDITE 14-2) was applied. Its mechanical elements are fixed together using titanium and stainless steel screws. Spot shielding was appropriately introduced, regarding the radiation requirements for electronic components inside TC-2 (determined using the software tool ESABASE/DOSRAD).

The electrical connection between the Sensor Head and the Electronic Box is formed using a multi-pole connector which directly connects the FRONT board to the Mother Board. The HV connection is separately realized, using two custom designed connectors that directly connect the deflection system to the HV board. The Data Processing Unit and Power Distribution boards, which interface with the spacecraft, are each equipped with auxiliary sub-panels that carry the spacecraft connectors. These connectors can be seen in Fig. 10 (right) protruding from the back panel of the electronic box.

\subsection{The electronic design}

The parallel layout adopted for the FRONT board (see the simplified block diagram in Fig. 11), was selected to militate against possible cross talk produced due to particle/electromagnetic interference on-orbit, and or single detector damage/failure. In this regard, each detector has its own analogue signal conditioning electronics; a 4-channel pulse height analyzer (discriminator stack) and four 8-bit counters to support the recording of individual events. Each counter has a hardware stop to prevent overflow and is set to stop counting at a value of $255\left(\mathrm{FF}_{\text {hex }}\right)$. At those locations along the orbit where the instrument operates (above the radiation belts and during south polar transits), it is very improbable that this value would be reached due to ENA events.

The Data Processing Unit (DPU) is a rad-hard 80C85 microprocessor supporting $128 \mathrm{kB}$ of RAM memory, $32 \mathrm{kB}$ of EEPROM memory and an $8 \mathrm{kB}$ rad-hard PROM memory. The command and data interface employs a MILSTD-1553B bus system and, for this, a single hybrid interface Remote Terminal Unit (RTU) is utilized with insulating transformers. Connection to the $1553 \mathrm{~B}$ bus line is performed using a standard, long stub, configuration $(\mathrm{Zo}=70 \Omega)$. The DPU Operating System (OS) software runs in one of four $32 \mathrm{kB}$ banks contained in a $128 \mathrm{kB}$ RAM memory that is downloaded from the rad-hard PROM. Three emergency copies of the OS are located in the EEPROM memory, together with various important system parameters. 


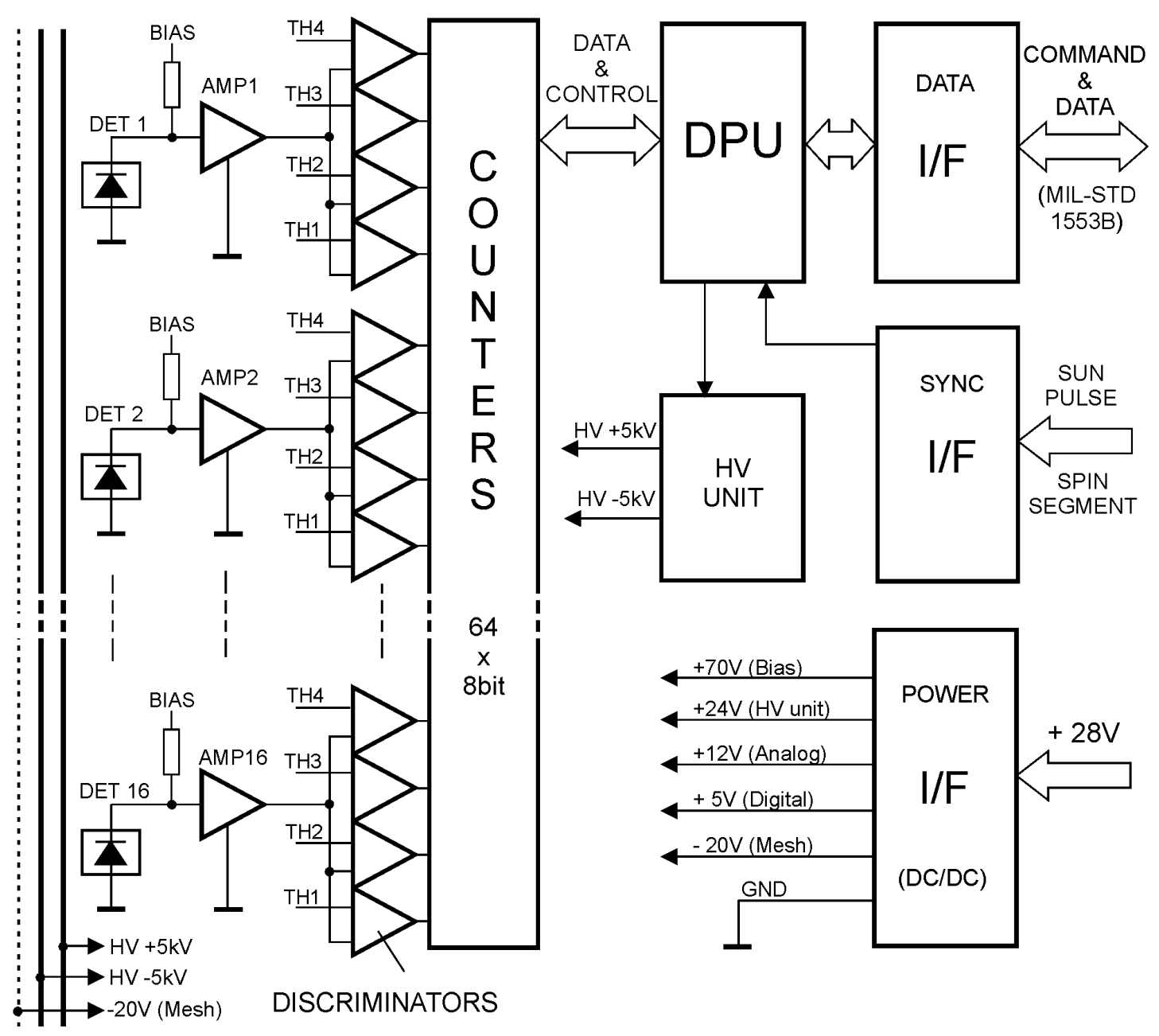

Fig. 11. Simplified functional block diagram of the NUADU imager.

\subsection{On-orbit operations}

The instrument starts to operate after POWER-ON with all its system parameters maintained according to the last telecommands received during the previous operation session (these are automatically saved in the EEPROM). The instrument then issues a standard frame consisting of 16 bytes of HK information; 8196 bytes of scientific (image) data; and one checksum byte. An image data frame is produced on integrating $\mathrm{N}$ complete images, according to the available telemetry quota.

Tele-commands allow modifications to be introduced during instrument operation. These include the setting of: Integration Mode (possible on-orbit values are $\mathrm{N}=1-32$ ); Toggle Mode; HV control; threshold control of energy channel 1 and Self-Test initialization. A set of "technical" tele-commands initiates such activities as: memory dump; issue of an image test pattern; EEPROM re-programming (software patching), etc.

\subsection{NUADU data products}

For the Double Star Data Center (DSDS), NUADU provides the same set of parameters for both the Prime Parameter (PP) and Summary Parameter (SP) databases. Table 3 summarizes relevant information concerning these parameters.

The fluxes are integrals of the differential flux $j(E)$ from the lower energy threshold to the upper energy threshold in each energy band (see Table 2). For a gyrotropic distribution the integral is given by:

$$
j(E)=\int_{E_{i}} d E \int_{-\pi / 2}^{\pi / 2} j(E, \theta) 2 \pi \sin \theta d \theta
$$

which provides omni-directional fluxes that represent averages obtained from the 16 detectors at 128 azimuths. 
Table 3. NUADU database parameters.

\begin{tabular}{|c|c|c|c|c|c|}
\hline \multicolumn{6}{|c|}{ (3-letter code: NUA; TC-2 only) } \\
\hline Name & Description & Units & Bytes & PP & SP \\
\hline Epoch & Time tag & $\mathrm{ms}$ & 8 & & - \\
\hline Status & Instrument status & & $1 / 16 \mathrm{~s}(\mathrm{PP}) 1 / 1 \min (\mathrm{SP})$ & - & - \\
\hline $\begin{array}{l}\text { J_ENA_E1 } \\
\text { J_ENA_E2 } \\
\text { J_ENA_E3 } \\
\text { J_ENA_E4 }\end{array}$ & $\begin{array}{l}\text { Omni-directional ENA flux } \\
\text { for all } 4 \text { energy bands }\end{array}$ & $\mathrm{cm}^{-2} \mathrm{~s}^{-1}$ & $4 \times 4 / 1 \min (\mathrm{SP})$ & - & $\bullet$ \\
\hline
\end{tabular}

\section{The scientific objectives of NUADU}

The history of ENA measurements at the Earth indicates the value of this technique in obtaining insights into the dynamics of the storm-time ring current; see, for example, accounts of ENA data recorded aboard the IMP-7, IMP-8 and ISEE-1 spacecraft (Williams et al., 1978; Roelof et al., 1985; Roelof, 1987); aboard CRRES (Voss et al., 1992, 1993); aboard Geotail (Lui et al., 1996; Wilken et al., 1997a; Orsini et al., 2000); aboard ASTRID (Barabash et al., 1997; Brandt et al., 1999); aboard CLUSTER (Wilken et al., 1997b); aboard POLAR (Blake et al., 1995; Henderson et al., 1997) and, most recently, aboard IMAGE (Burch, 2003).

The NUADU instrument can be used in "stand-alone" mode to investigate a wide range of physical problems and has the following purposes:

1. To monitor the morphology of the ring current under different magnetospheric conditions and, thereby, characterise the inner magnetosphere;

2. To study particle energization processes in the inner magnetosphere and image plasma convection and substorm injections;

3. To study the interaction of the ring current with the upper atmosphere;

4. To investigate the interrelationship between the ring current and the electric field of the inner magnetosphere.

The latter objective is achieved through comparing the morphology of the ring current with models that incorporate coupling between the ring current and the ionosphere (see, e.g. Fok et al., 2003). See also the account of NUADU science contained in McKenna-Lawlor et al. (2005).

\subsection{Multipoint observations}

Several advantages accrue to using simultaneous ENA images obtained from different vantage points. First, it increases the coverage of parts of the ring current that may otherwise be obscured by the Earth. Second, in any retrieval procedure the use of several vantage points increases the certainty of the result. Third, it is not possible to obtain exact information about the pitch-angle distributions (PADs) of the parent ions using only a single vantage point. Several vantage points allow for a more comprehensive retrieval of the PAD. This has never been achieved using real data. Unpublished tests with IMAGE/HENA data used several different points along the IMAGE orbit during a stable recovery phase. The images from these points were then inverted and it was found that the resulting PAD peaked at around $90^{\circ}$ (as would be expected for a recovery phase ring current).

The full potential of global imaging cannot be fully utilised until in-situ measurements can be successfully incorporated in the analysis of global data. For example, with an ENA imager located at a polar position, one obtains the best local time and radial coverage of the ring current. However, since the ENA flux falls off rapidly with altitude, the gradients of the ring current at high-altitudes are associated with greater uncertainties than those at lower altitudes where the ENA flux is stronger. In-situ measurements of the ring current in the equatorial plane provide constraints that can be used in the analysis of ENA images, so that the high-altitude regions with low ENA fluxes can be properly bounded.

In the spirit of an agreement between the Chinese and European Space Agencies, NUADU can work in concert with instruments on CLUSTER to support the scientific objectives of this mission. In tandem, NUADU science could, in principle, itself be supported by the possibility to validate ion distributions retrieved from ENA data through using insitu ion measurements recorded by CLUSTER instruments. There is, however, no overlap with the energy range covered by the Cluster Ion Spectrometry (CIS) experiment (Reme et al., 2001), since CIS detects ions only up to $\sim 40 \mathrm{keV}$. Also, although the RAPID experiment (Wilken et al., 1997b), which measures ions in the range $20-400 \mathrm{keV}$, provides an overlap with the energy range covered by NUADU, these data are not presently available, since RAPID's calibrations are presently undergoing a re-evaluation. Relevant ion data recorded aboard TC- 2 itself will be made available when they are calibrated (J.-B. Cao, private communication). Other insitu measurements are available from the proton detectors on board the geo-synchronous Los Alamos National Laboratory (LANL) satellites and from the Imaging Proton Spectrometer (IPS) on board the POLAR satellite (Blake et al., 1995). 

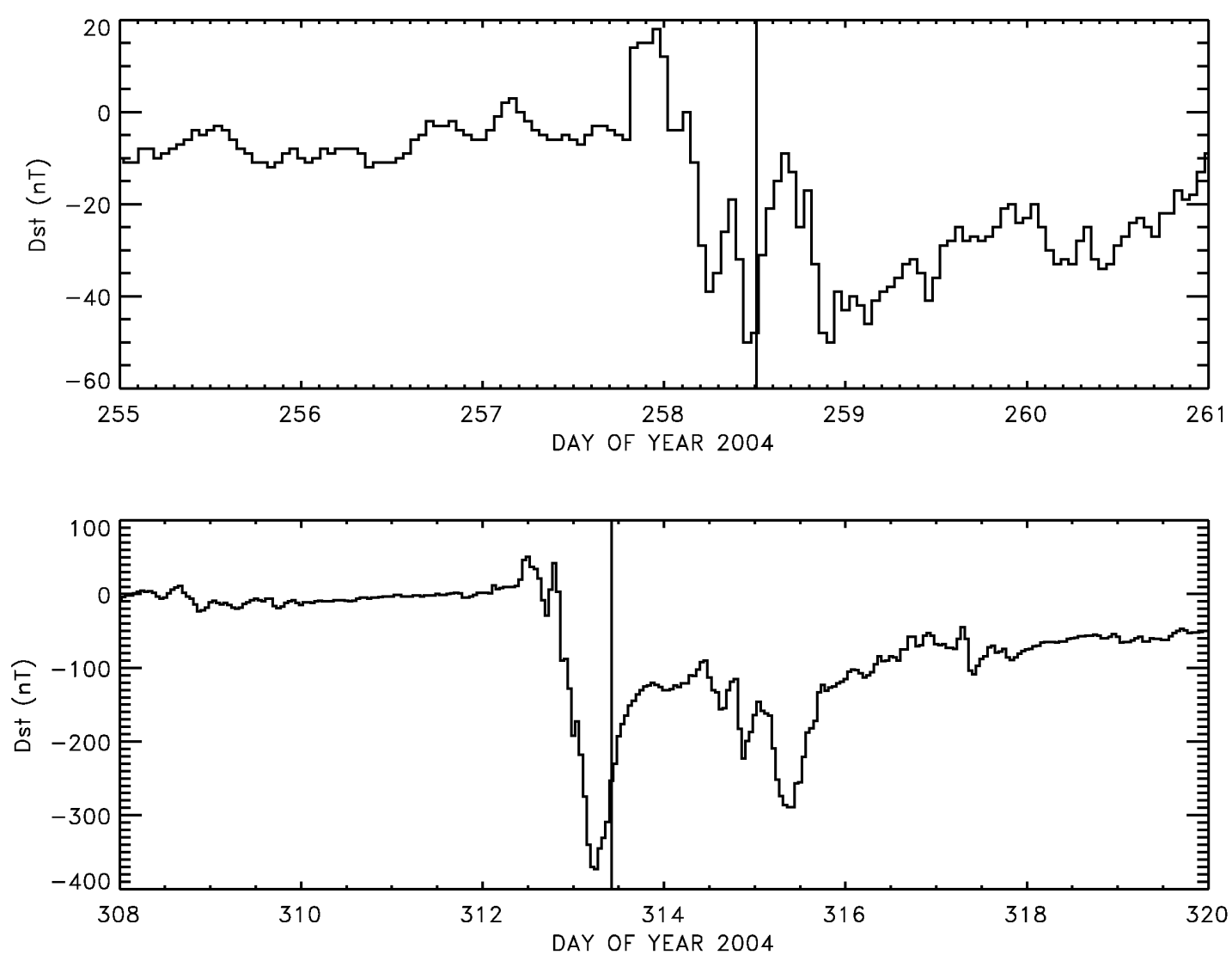

Fig. 12. Dst index covering the magnetic storms of September 2004 and November 2004. The vertical lines appearing on these records indicate times when the ENA images presented in Figs. 13 and 23 were initiated.

In early 2005, the apogee of IMAGE approached $90^{\circ}$ magnetic latitude. Perigee passes of IMAGE then provided low-altitude measurements, characterised by high spatial and temporal resolution. By appropriately combining NUADU (polar) information with HENA measurements during this favourable orbit configuration, information concerning the interaction between the ring current and the Earth's upper atmosphere can be derived.

It is also possible by combining observations made by one of these ENA imagers while the other is traversing the radiation belts, to co-operatively secure more complete coverage of dynamic changes in the ring current than can be achieved using one instrument alone. In December 2005, when TC2 and IMAGE will both be at locations allowing NUADU and HENA to simultaneously view the Southern Hemisphere, ring current stereo images can potentially be obtained, should a geomagnetic storm, fortuitously, occur.

\section{NUADU observations}

In the first, approximately six months since the launch of DSP-Polar, several geomagnetic storms took place. The first of these events occurred during the commissioning phase of
NUADU in September 2004 and the second in November 2004. In what follows, against the background of the state of the interplanetary medium pertaining to each of these occasions, the ENA images that were associatively recorded are presented and discussed.

\subsection{Interplanetary and geomagnetic conditions (September 2004)}

On 12 September 2004 two M-class flares took place consecutively in Active Region 0672 at N03, E49. The first, an M4 8/2N event, was observed from 00:04-01:33 UT by GOES/XRA (whole disk). This flare was associated with metric Type II burst radiation and the related shock speed was estimated (by observers at Learmonth) to be $800 \mathrm{~km} / \mathrm{s}$. The second flare was an impulsive M3.2/SN event recorded by GOES 12/SX from 01:39-01:40 UT. Again, a metric Type II burst was produced and the related shock speed (also estimated at Learmonth) was $750 \mathrm{~km} / \mathrm{s}$.

Figure 12 (top) shows variations in the Dst index recorded during the period concerned at Kyoto University. Dst is a geomagnetic index used to monitor worldwide magnetic storm activity. It is constructed by averaging the horizontal component of the geomagnetic field from mid-latitude and from 

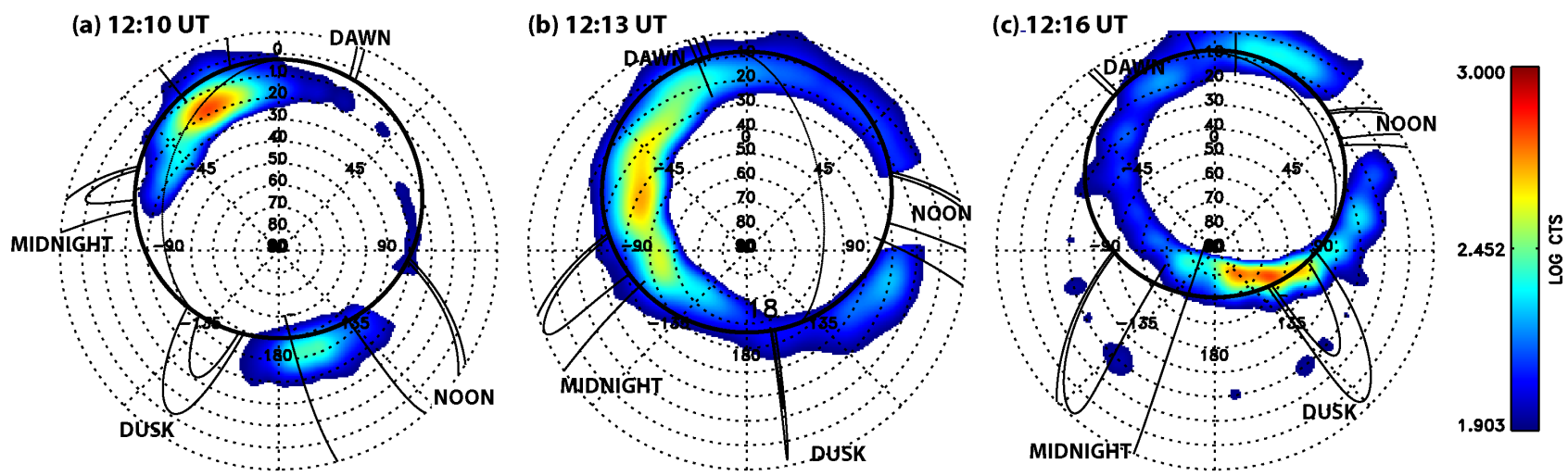

Fig. 13. A sequence of plots showing ENA emissions recorded by NUADU on 14 September 2004 while traversing the south polar cap. The SM co-ordinate system utilised has its Z-axis parallel to the dipole axis of the Earth; the XZ plane contains the Earth-Sun direction and the $\mathrm{Y}$ axis is perpendicular to the Earth-Sun line towards dusk. The image is displayed in an equidistant, azimuthal, projection. The solid circle represents the limb of the Earth and the terminator is depicted by a solid line. The dipole field lines of L-shells 4 and 8 are drawn at four local times for reference. The dotted background grid represents the instrumental co-ordinates of the NUADU instrument. The radial direction of the grid is the FWHM of the sector's response, and the azimuthal direction is the spin direction.

equatorial magnetograms recorded globally. Negative Dst indicates the presence of a magnetic storm and, the more negative this value is, the more intense the magnetic storm in question is. Only when there is an eastward electric field in the solar wind, which corresponds to a southward directed Interplanetary Magnetic Field (IMF), is there a ring current injection that results in the stimulation of a negative change in the Dst index. This negative value has its origin in the "storm-time", pressure driven, ring current that flows around the Earth from east to west in the equatorial plane.

Dst contains contributions from: the magnetopause current; the partial and symmetric ring currents, the substorm current wedge; the magnetotail currents and from induced currents in the diamagnetic Earth. In detailed work, Dst*, the global perturbation from near-Earth currents, is derived by correcting the Dst index for magnetopause current contributions and for induced currents in the solid Earth using:

Dst $^{*}=\left(\right.$ Dst $\left.-\mathrm{D}_{\mathrm{MP}}+\mathrm{D}_{\mathrm{QRC}}\right) / \mathrm{C}_{\mathrm{IC}}$,

where $\mathrm{D}_{\mathrm{MP}}$ is the perturbation from the Chapman-Ferraro currents on the magnetopause; $\mathrm{D}_{\mathrm{QRC}}$ is the contribution from the quiet time ring current (which is subtracted out as a baseline offset of Dst), and $\mathrm{C}_{\mathrm{IC}}$ is the correction due to induced currents in the Earth (McPherron, 1997; Kozyra et al., 1998; Kozyra and Liemohn, 2003).

In the present text, which concerns qualitative comparisons with ENA data, we utilize only the uncorrected Dst index plotted in Fig. 12. This moderate perturbation, which commenced at approximately 21:00 UT on 13 September 2004, displayed two episodes in the course of which, on 14 September, the index decreased in the first instance to $-40 \mathrm{nT}$. Later, following a partial recovery, it decreased again to $-50 \mathrm{nT}$. It is surmised that the effects of a second flare that occurred (see above) within the same active region supplemented the particles and shocks associated with the first event, and contributed to prolonging the overall duration of the initial Dst disturbance.

\subsubsection{NUADU observations}

Figure 13 shows three Hydrogen ENA images recorded by NUADU in the $50-81 \mathrm{keV}$ range during a perigee pass over the south pole at an altitude of approximately $600 \mathrm{~km}$ close to noon on 14 September 2004 (the vertical line on the Dst Index in Fig. 12 (top) shows that, at the time when these images were acquired, this index was in rapid recovery following the second of the two closely related decreases described above).

The SM co-ordinate system utilised in Fig. 13 has its Zaxis parallel to the dipole axis of the Earth; the $\mathrm{XZ}$ plane contains the Earth-Sun direction and the $\mathrm{Y}$ axis is perpendicular to the Earth-Sun line towards dusk. The image is displayed in an equidistant, azimuthal projection and is close to what a human eye would see. The solid circle represents the limb of the Earth and the terminator is depicted by a solid line. The dipole field lines of L-shells 4 and 8 are drawn at four local times for reference. The dotted background grid represents the instrumental co-ordinates of the NUADU instrument. The radial direction of the grid is the FWHM of the sector's response (see also Fig. 4), and the azimuthal direction is the spin direction.

The images show the interaction between ring current ions and the dense upper atmosphere. Since the low-altitude ENA flux (resulting from charge exchange with the hydrogen geocorona), is about two orders of magnitude higher than the ENA fluxes typically recorded during a north polar pass, (see the relevant discussion of Roelof, 1997a), the required integration time for each image was only $16 \mathrm{~s}$.

Figure 14 illustrates the approximate viewing geometry of NUADU during a typical perigee pass and, thereby, explains why it is the case that the bright ENA emissions recorded by the instrument originated on the opposite side of the dipole 


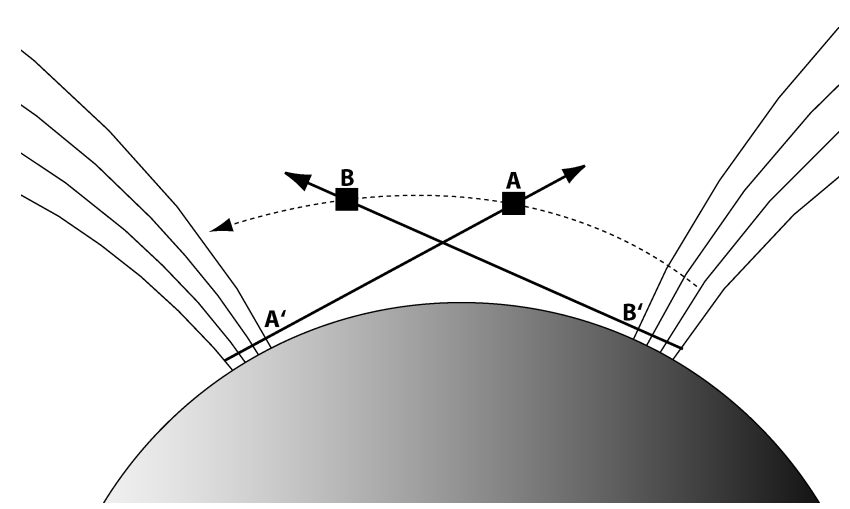

Fig. 14. Viewing geometry during a typical south polar perigee pass of TC-2.

axis to that occupied by the spacecraft. In this representation, ions spiral down the terrestrial field lines and charge exchange with the dense upper atmosphere. The location of these ENA emissions is weighted by the fact that the heaviest precipitation occurs close to midnight. The maximum ENA emissions produced travel, approximately, perpendicular to the field lines at an altitude of about $350 \mathrm{~km}$. Consequently, NUADU on TC-2, which orbits at an altitude of around $600 \mathrm{~km}$, will detect when at position (A) bright ENA emissions coming from the field lines on the far side of the Earth $\left(\mathrm{A}^{\prime}\right)$ relative to the spacecraft's position. Not until TC2 has reached position (B) will NUADU detect bright ENA emissions coming from the field lines it has just traversed $\left(\mathrm{B}^{\prime}\right)$. Although the exact geometry and distribution of the low-altitude emissions is, in actuality, far more complicated than the situation depicted in the figure, this picture is, none the less, qualitatively correct. It was assumed in this regard that the spin axis pointed exactly in the direction of ecliptic south. The exact direction of the spin axis of TC-2 is, in actuality, somewhat uncertain, although it is estimated that, by 14 September, it had drifted by a few degrees since the launch. Therefore, it is not unlikely that the low-altitude ENA images displayed in Fig. 14 are slightly offset.

The ENA emissions recorded at 12:10 UT (Fig. 13, left), came from the sector midnight-to-dawn. This is consistent with the interpretation provided by Fig. 14, as can be crosschecked using the orbit plot in Fig. 15 which shows, in red, in the SM system, the TC-2 trajectory with tick marks every $5 \mathrm{~min}$. The position of TC-2 at 12:10 UT is designated by a blue circle. Magnetic field lines (following Tsyganenko et al., 2003) are also represented. Six minutes later when the spacecraft has moved "upward" in this plot, the emissions should have, correspondingly, moved "downward". This is exactly what is shown by the data of Fig. $13 \mathrm{c}$ and is consistent with the representation provided in Fig. 14.

As already noted, the ENA images displayed in Fig. 13 were taken when the Dst index, having reached a maximum value of $\sim-50 \mathrm{nT}$, was rapidly recovering. Although, thereafter, the low-latitude ENA emissions decayed in intensity as the ring current faded, even small variations in Dst were reflected in further emission enhancements in ENAs.

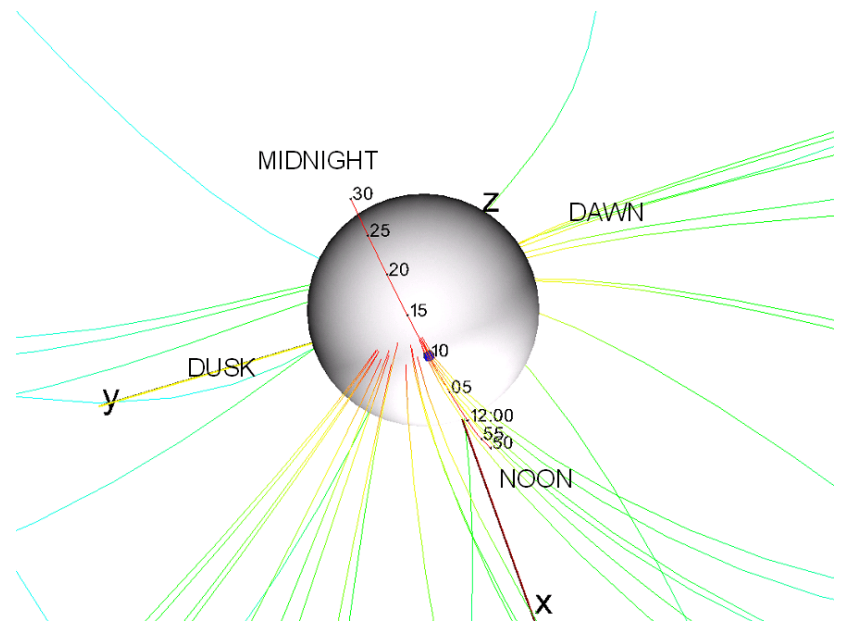

Fig. 15. The trajectory of TC-2 near perigee in the SM system on 14 September 2004 (11:50:00-12:30:00 UT) plotted using OVT software (http://ovt.irf.use). Tick marks are provided every $5 \mathrm{~min}$. The position of the spacecraft at 12:10 UT is indicated by a blue circle. The magnetic field lines follow the model of Tsyganenko et al. (2003).

The ENA production rate close to the exobase for nearly mirroring ions may be estimated using an analytical expression derived by Roelof (1997b), for the case of single chargeexchange between ions and exospheric neutrals; see also related papers by De Michelis et al. (1997) and Asamura et al. (1999). In order to find out how many ENAs are produced by ions travelling from the equator into the upper atmosphere, we consider below the ENA flux per unit Line of Sight (LOS) length in the immediate vicinity of a field line at different altitudes along the field line;

$\frac{\partial j_{\mathrm{ENA}}}{\partial \ell}=\frac{j_{\mathrm{ION}}^{e q}}{\lambda_{\mathrm{ION}}} \exp \left[-\int_{s}^{s_{e q}} \frac{d s^{\prime}}{\mu \lambda_{\mathrm{ION}}}\right]$,

where the integral in the exponent describes the attenuation of ions due to charge exchange and is taken from along the field line from the equator to the interaction point. The mean free path length of ions is denoted by $\lambda_{\text {ION }}$. The ENA production function $\delta j_{\mathrm{ENA}} / \delta 1 \cdot R_{E} / j_{\mathrm{ION}}^{e q}$ (where $R_{E}$ is the radius of the Earth $=6378 \mathrm{~km}$ ) is plotted in Fig. 16 for $40 \mathrm{keV} \mathrm{H}^{+}$ ions as a function of altitude at different values of $\mu$ in an exosphere composed of $\mathrm{H}, \mathrm{He}, \mathrm{N}, \mathrm{O}, \mathrm{N}_{2}$ and $\mathrm{O}_{2}$. The altitude of maximum ENA emissions is a strong function of ion pitch angle $(\mu)$ and of the altitude for a given $\mathrm{L}$ value of the field line. This plot shows that the layer in which most of the ENA production takes place is of the order of $100 \mathrm{~km}$ thick, and that it drops off sharply $(\leq 50 \mathrm{~km})$ towards lower altitudes. At the altitude of TC-2 and close to the magnetic pole, there is good MLT coverage of this layer.

\subsection{Solar circumstances in November 2004}

Some 4.5 years after the peak month of Solar Cycle 23 (April 2000), and just two years from the predicted time of 


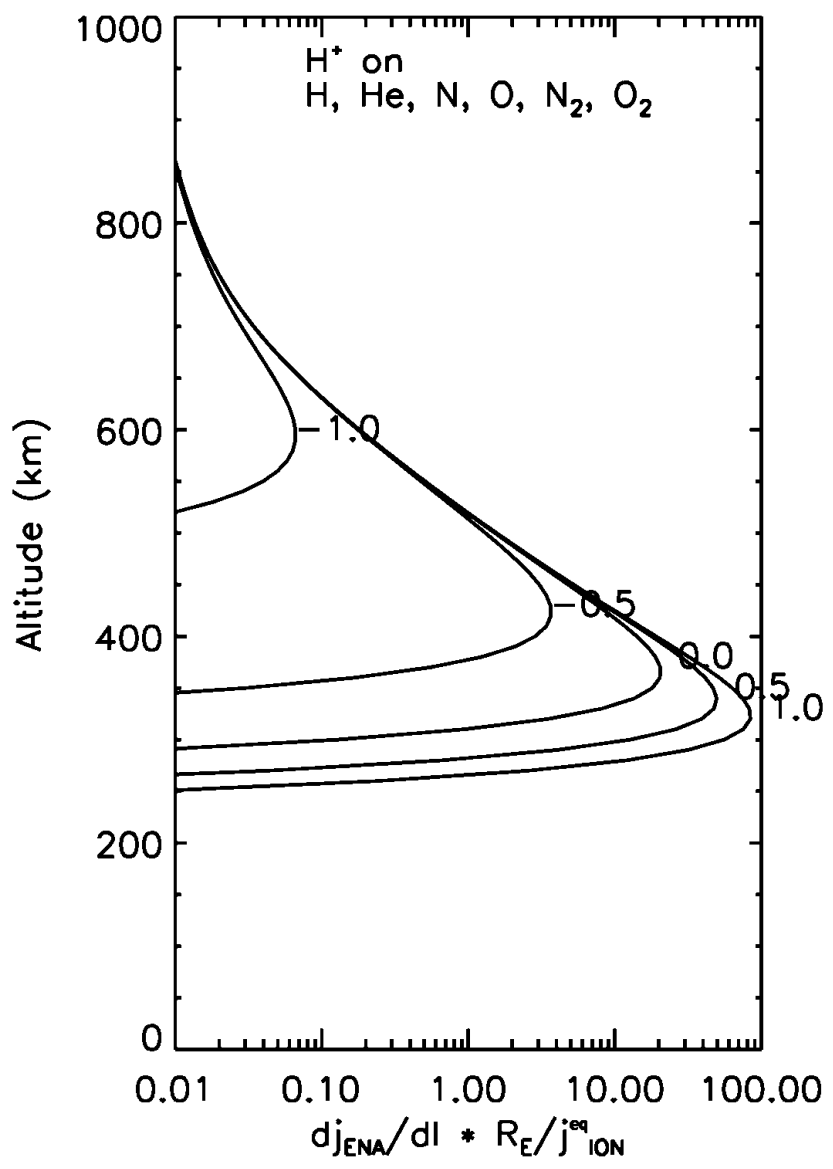

Fig. 16. The ENA production function $\partial j_{\mathrm{ENA}} / \partial 1 \cdot \mathrm{R}_{E} / j_{\mathrm{ION}}^{e q}$ (see the text) for $40 \mathrm{keV} \mathrm{H}^{+}$ions plotted as a function of altitude for various values of the pitch angle, assuming a six-component exosphere $(\mathrm{H}$, $\mathrm{He}, \mathrm{N}, \mathrm{O}, \mathrm{N}_{2}$ and $\mathrm{O}_{2}$ ).

solar minimum (Autumn 2006), a sequence of large flares was recorded, from 4 November 2004, in NOAA Active Region 696. Information concerning several of these events is provided in Table 4. The first flare listed was accompanied by a Coronal Mass Ejection (CME) showing a Plane of Sky (POS) speed of $\sim 1000 \mathrm{~km} / \mathrm{s}$. A metric Type II burst was produced in addition, and its related shock speed was estimated at Culgoora (from the burst drift rate) to be $\sim 600 \mathrm{~km} / \mathrm{s}$. Succeeding major events at the same location were also characterized by CME and Type II burst activity until, as west limb passage of the active region approached, a new source of activity in the southern solar hemisphere became dominant (an example is provided by Event 5 in Table 4).

\subsubsection{Interplanetary and geomagnetic activity}

Figure 17 shows variations in the solar wind bulk speed recorded aboard NASA's Advanced Composition Explorer (ACE) spacecraft (at L1), from 6-14 November 2004. It is seen that, on 7 November, the solar wind speed increased above its background level by a factor of approximately two. Thereafter, following a short initial decline, a further en-

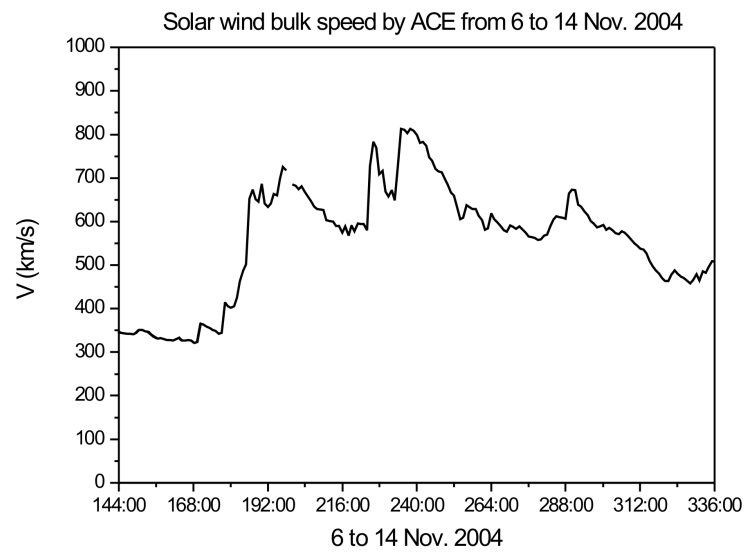

Fig. 17. Solar wind bulk speed recorded aboard the ACE spacecraft from 6-14 November 2004.

hancement, displaying two significant peaks, was recorded in the interval 8-10 November. On 12 November a further, relatively minor increase in the solar wind speed took place.

The arrival of an interplanetary shock was recorded aboard ACE at 16:28 UT on 7 November. Thereafter, the Interplanetary Magnetic Field (IMF) turned southward in two steps $(B \mathrm{z}=-20 \mathrm{nT}$ at 19:30 UT and $B \mathrm{z}=-50 \mathrm{nT}$ at 22:30 UT, see Fig. 18). At 05:38 UT on 9 November, the arrival of another shock was recorded at the Polar Orbital Environmental Satellite (POES), with a measured strength of 562 Giga Watts. This was followed by a further shock at 07:22 UT, with measured strength 419.4 Giga Watts. These latter two events, like the earlier shock on 7 November, were preceded by CME activity in AR 696. Also, the IMF (Fig. 18) showed related excursions on 9 and 10 November to approximately $-20 \mathrm{nT}$.

Plots presented in Fig. 19 show proton (left) and electron (right) data recorded in the $\mathrm{MeV}$ range aboard the Geostationary Operational Environmental Satellite GOES 11, on $7-$ 10 November 2004 (top) and on 8-12 November 2004 (bottom). Of special interest are the two large increases recorded in $>100 \mathrm{MeV}$ protons (which were individually associated with X2 flares on 7 and 10 November, see Table 4). Such particles rarely rise above the 0.1 level on such a plot. Also present (Fig. 19, right) were substantial fluxes of $>2 \mathrm{MeV}$ electrons which persisted for some eleven days.

On 8 November, a CME that exited the Sun on the previous day, arrived at the Earth and greatly compressed the magnetosphere. A major magnetic storm ensued and Fig. 12 (bottom) shows the Dst index recorded at Kyoto University during the relevant period. It is noted that the maximum value of the Dst Index $(-383 \mathrm{nT})$ attained on 8 November during this magnetic storm, is among the strongest ever recorded. Thereafter, during the recovery phase of this event, further perturbations, occasioned by the consequences of renewed flaring in AR 696, were recorded on 9/10 November. A further, relatively minor event on 12 November was associated with 
Table 4. Sequence of large flares recorded in NOAA Active Region 696.

\begin{tabular}{cccccc}
\hline Event & November 2004 Day / start UT & Location & Vsh & Opt.Class & X-ray class \\
\hline 1 & $06 / 00: 36$ & N09, E05 & 1000 & 2 N & M9.3 \\
2 & $07 / 15: 59$ & N09, W17 & 697 & - & X2.0 \\
3 & $09 / 17: 24$ & N09, W51 & 1866 & - & X8.9 \\
4 & $10 / 02: 07$ & N10, W47 & 2100 & $3 B$ & X2.5 \\
5 & $12 / 09: 57$ & S14, E37 & 553 & - & - \\
\hline
\end{tabular}

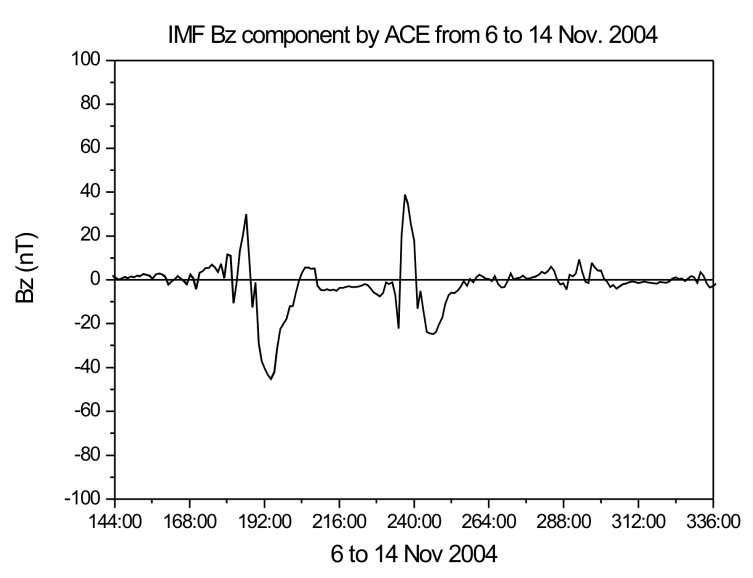

Fig. 18. The IMF $B z$ component recorded aboard the ACE spacecraft from 6-14 November 2004.

activity in a region located in the southern solar hemisphere (Event 5, Table 4). It is noted that the two large excursions in Dst displayed in Fig. 12 (bottom) corresponded to significant changes in the rigidity of flare related protons recorded at two ground stations in Slovakia, while increases in cosmic ray particle transparency were also associatively recorded (K. Kudela, private communication). Figure 20 presents complementary large-scale variations recorded in the estimated planetary $\mathrm{Kp}$ index in the interval 7-11 November 2004.

6.2.2 Particle data in geosynchronous and in low-altitude orbits

Figure 21 shows proton fluxes recorded aboard the Synchronous Orbit Particle Analyzer (SOPA) flown at an altitude of $\sim 42000 \mathrm{~km}$ aboard several Los Alamos National Laboratory (LANL) spacecraft from 6-13 November (energy range $30 \mathrm{keV}$ to several hundred $\mathrm{keV}$ ). On comparing the fluxes measured at geosynchronous orbit with proton fluxes recorded aboard NOAA satellites flying at $\sim 800 \mathrm{~km} / \mathrm{s}$, it was found that, at the two locations, these fluxes did not vary coherently (W. Murtagh, private communication). In particular, proton fluxes (30-80 keV) recorded by the NOAA spacecraft were characterized by a rapid enhancement during the main storm phase, and these fluxes decayed when the storm entered its decay phase. Proton fluxes in the same energy range recorded at geosynchronous orbit also rose rapidly at the start of the main phase of the storm but they did not decay significantly until after the main phase had terminated.

With respect to local time dependence, during the early main phase of the storm, fluxes recorded aboard the NOAA spacecraft (beyond $\mathrm{L}=5$ ) initially increased in the evening to the pre-midnight sector. Thereafter, a flux enhancement in the post-midnight to morning sector took place after a time delay of several hours. As the storm entered its late main phase, the proton fluxes dropped away in the evening to the pre-midnight sector, before the main phase had ended. In the post-midnight to morning sectors, they decayed away at the end of the main phase. This shift with respect to local time in proton precipitation was closely associated with a change in the intensity of the southward component of the IMF.

One of the effects characterizing a geomagnetic storm is the increase in high energy proton bombardment experienced at terrestrial locations facing the Sun. This is especially the case in the South Atlantic Anomaly (SAA), which, in such circumstances, normally displays heightened levels of solar particle incidence. Figure 22, which displays proton data recorded by the Solar Environmental Monitor (SEM) aboard NOAA-16, while executing a circular, Sun-synchronous polar orbit at a nominal flight height of $833 \mathrm{~km}$ between 7-8 November and 9-10 November, illustrates this behaviour.

At geosynchronous orbit (Fig. 21) the enhancement of proton fluxes during the main phase was reasonably coherent all over the night-time sector and showed little variation in the other time sectors mentioned above. From this it can be inferred that the enhanced proton fluxes associated with the main storm phase persisted at the equator from the beginning of the storm main phase through its late recovery phase. The pitch-angle scattering processes, on the other hand, which cause equatorially trapped protons to precipitate to NOAA spacecraft latitudes, were activated only during the main phase, thereby resulting in a significant difference in the proton fluxes measured at the altitude of the NOAA satellites between the main and recovery phases.

It can be deduced, regarding the local time dependence of the proton fluxes recorded, that the region of enhanced pitch-angle scattering shifted from the dusk side to the dawn side during the main phase of the storm. A close correlation observed between proton fluxes and southward directed 

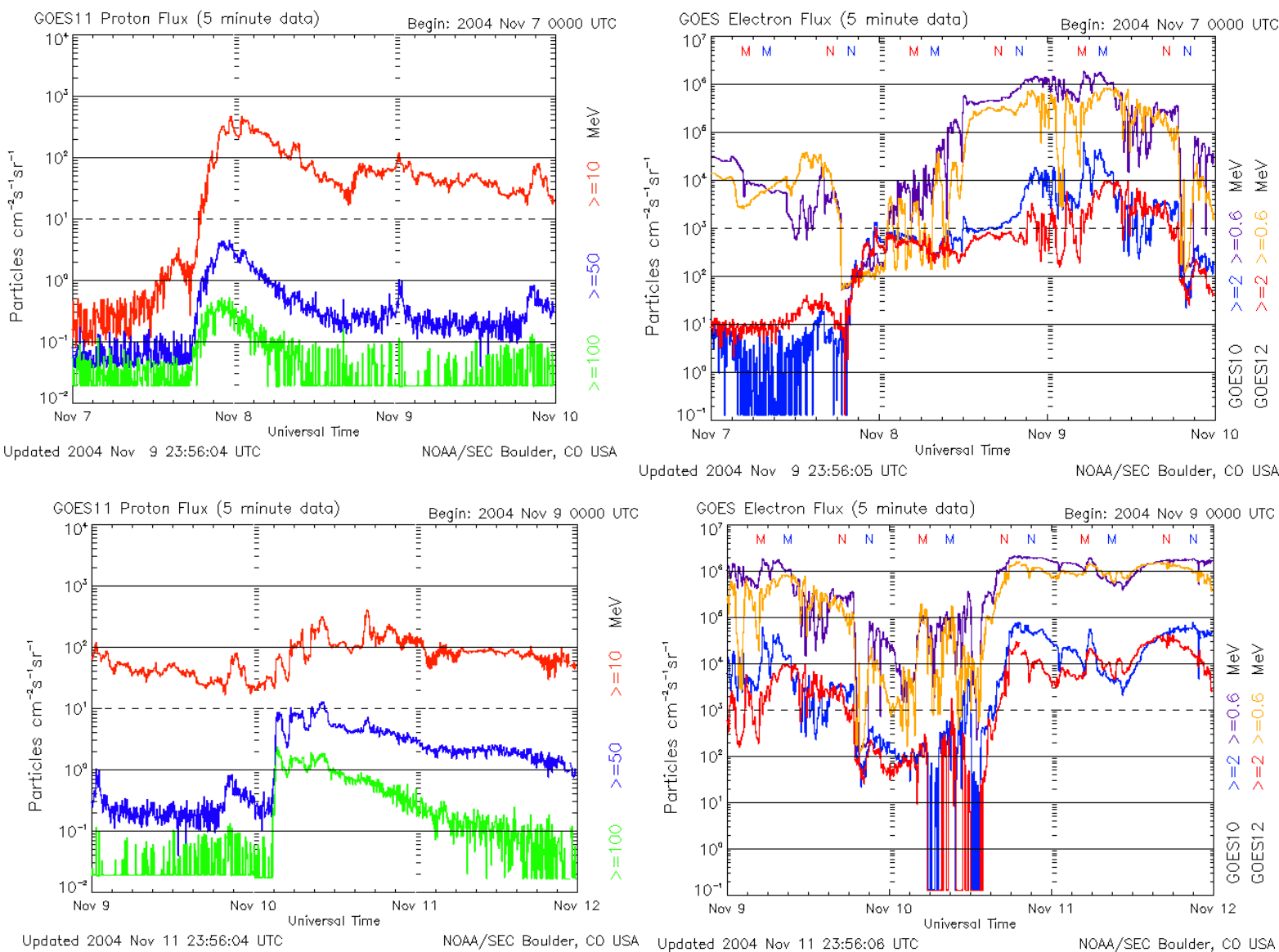

Fig. 19. (Top Left) GOES 11 (5-min) proton data recorded in three energy channels ( $>10 \mathrm{MeV},>50 \mathrm{MeV},>100 \mathrm{MeV}$ ); (Top, Right) GOES 10 and GOES 12 (5-min) electron data recorded in two energy channels ( $\geq 0.6$ and $\geq 2.0 \mathrm{MeV}$ ), all between 7-10 November 2004; (Bottom Left) corresponding proton data and (bottom right) corresponding electron data similarly recorded between 9-12 November 2004.

IMF suggests that the local time sector displaying enhanced pitch-angle scattering, was controlled by the intensity of the southward directed IMF component.

\subsubsection{NUADU observations}

Figure 23a (left) shows a NUADU image recorded from 10:10 UT on 8 November in the $81-158 \mathrm{keV}$ range during a 13-min integration period. This image was obtained at Solar Magnetic (SM) coordinates $[0.2,0.5,3.9] \mathrm{R}_{E}$. The presentation format is similar to that already described in Sect. 6.1.1. At that time, the Dst index was in an early stage of recovery (as indicated by the vertical line on the record of Fig. 12, bottom).

The bright spot in Fig. 23a at the foot of the midnight field lines denotes intense ENA emissions, produced where ring current ions charge exchanged with the dense upper atmosphere. This image illustrates that the ENA flux was concentrated near the Earth due to the pertaining, exponential, atmospheric density distribution. Also, from midnight and around dusk we see that the emissions were wrapped around the Earth. This is an ENA signature of the ring current flowing

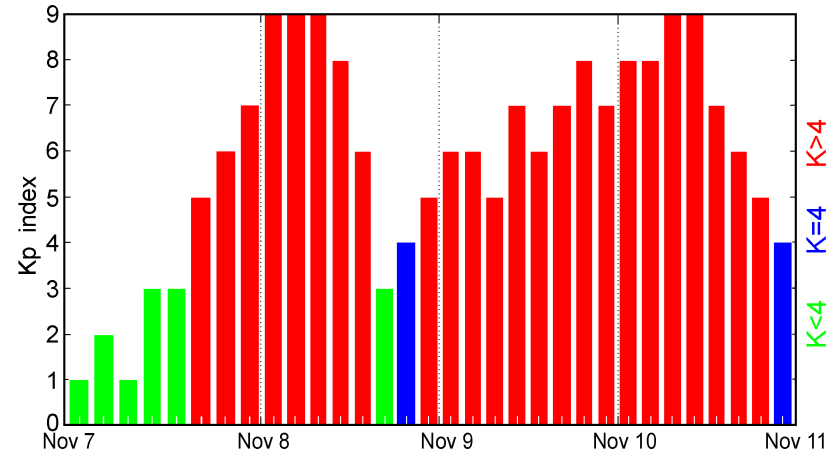

Fig. 20. The estimated planetary Kp Index from 7-11 November 2004. This index combines disturbances in the Earth's magnetic field measured at nine separate observatories in North America on a scale from 0-9. Each bar is for a three-hour interval in UT and Kp values below 4 indicate little disturbance. The bars are green when $\mathrm{Kp}<4$; blue when $\mathrm{Kp}=4$, and red when $\mathrm{Kp}>4$. Red bars indicate a storm warning. Values greater than 7 indicate a large disturbance. 


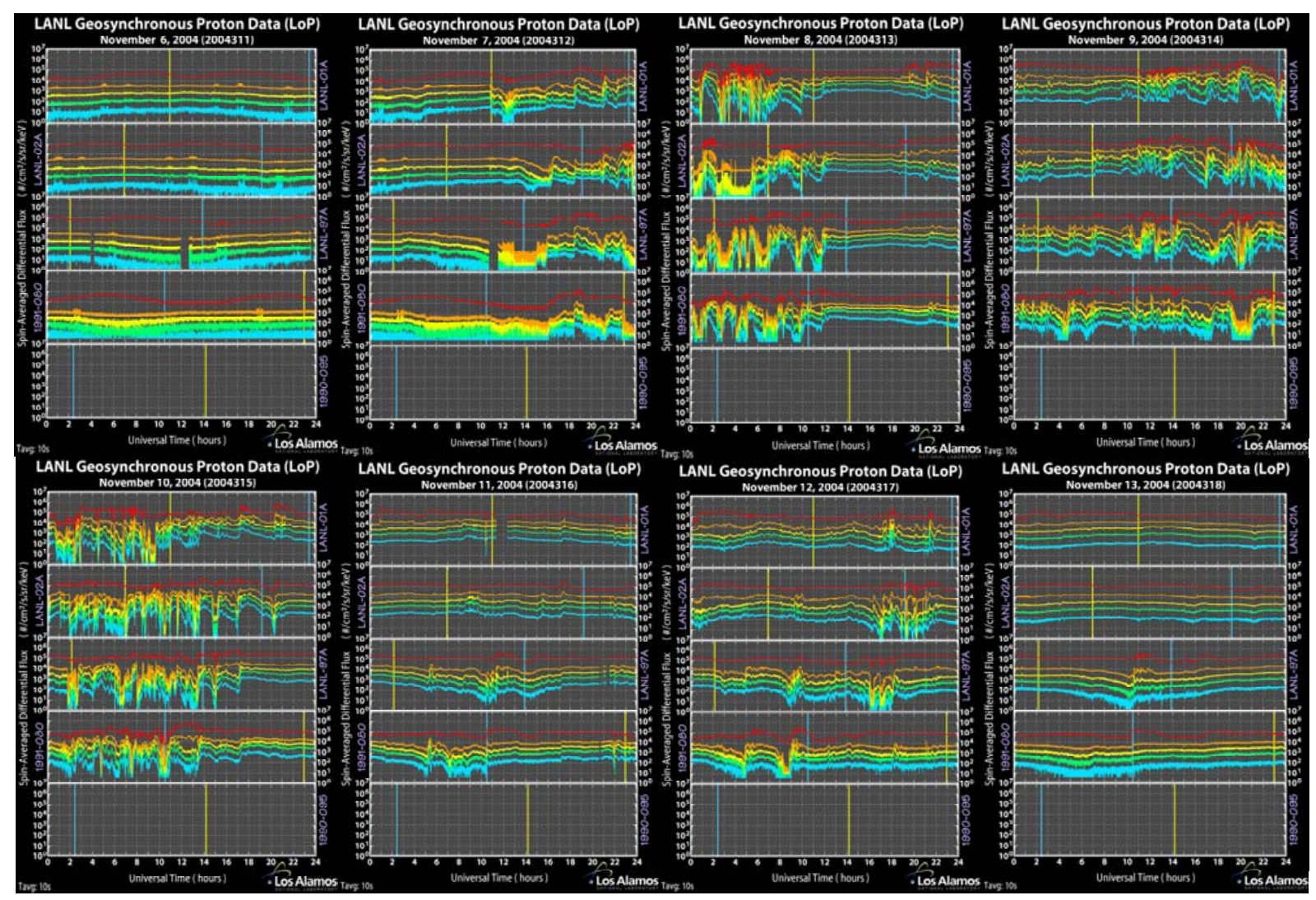

Fig. 21. Spin averaged (10s), differential, proton fluxes recorded in geosynchronous orbit aboard several LANL spacecraft between 6-13 November 2004 in channels $30-45 \mathrm{keV}, 50-75 \mathrm{keV}, 75-105 \mathrm{keV}, 105-150 \mathrm{keV}$ and 150-315 keV (bottom trace). Preliminary/quick-look data.

in from the plasma sheet at midnight (from around dusk) and out through the magnetopause (not seen). The ENA intensity is strong at midnight because of the high flux of the parent ions present. This is expected since ions gain energy when they move from regions of weaker to stronger magnetic fields through conserving their first adiabatic invariant. As they approach the inner magnetosphere, these particles are transported across magnetic field lines, primarily by gradient and curvature drift, as well as by $E \times B$ drift, in a combination of potential and induction electric fields. The region of enhanced intensity seen in the NUADU image presented in Fig. 23a constitutes, in effect, a "snapshot" recorded in ENAs of the locations of accelerated ions transiting the inner magnetosphere, en route to being lost through the magnetopause.

Figure 23b (right) shows the ENA image obtained simultaneously by IMAGE/HENA in the 60-119 keV range during a 20-min integration period. At this time the IMAGE satellite was below the Earth looking up at the south pole at SM position $[3.0,-2.5,-7.0] R_{E}$. We, again, see in this record the signature of low-altitude ENA emissions, where the ring current ions reached the upper atmosphere, and the general morphology displayed in the two images is consistent. Note how, again, in the HENA image the ring current was wrapped around the Earth from dusk and extended, thereafter, into the dayside before its constituents drifted out through the magnetopause.

\subsubsection{Note on composition}

NUADU does not separate different species of ENAs. However, since HENA is capable of separating Hydrogen from Oxygen and heavier ions (Krimigis et al., 2004), we can use simultaneously recorded data to estimate the mixing ratio between the Hydrogen and Oxygen detected in NUADU's energy range. The energy channels for $\mathrm{H}$ and $\mathrm{O}$ are described in Table 2. For example, the third energy channel detects $\mathrm{H}$ in the $81-158 \mathrm{keV}$ range and $\mathrm{O}$ in the $185-300 \mathrm{keV}$ channel. From HENA, the Hydrogen ENA flux around the 81$158 \mathrm{keV}$ range is typically (for storms) about two orders of magnitude higher than the Oxygen ENA flux at around the 185-300 keV range. This means that NUADU detected predominantly Hydrogen in its third energy channel. While there may be cases when the Oxygen ENA flux is exceptionally strong, in most storms NUADU will image Hydrogen exclusively.

\subsubsection{Ring current variations}

The ring current imaged by NUADU showed, in addition to the activity associated with the major interplanetary events and geomagnetic disturbance of 7 November 2004, enhancements and variations that reflected the occurrences of the later events of 9-10 November and 12 November already 

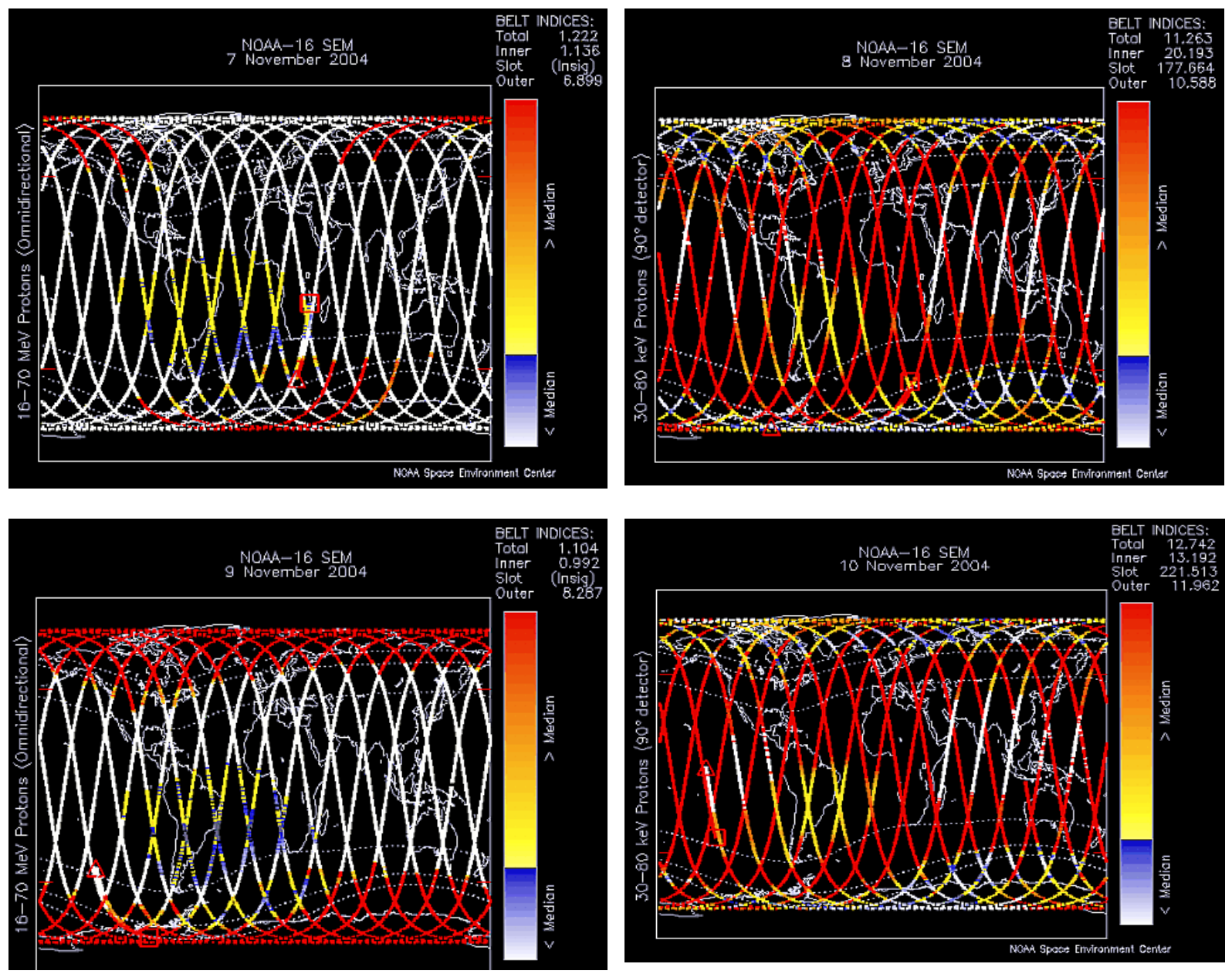

Fig. 22. Omni-directional $16-70 \mathrm{MeV}$ protons recorded aboard the NOAA-16 spacecraft between 7-8 November 2004 (top) and 9-10 November 2004 (bottom).

discussed above. These variations and correlations will be the subject of a detailed follow-up paper when the raw data concerned has been further processed.

Meanwhile, it can be noted that the flare associated ion injections recorded on 8 November by the LANL spacecraft were closely reflected in the ENA data. In particular, a shift in the region of enhanced pitch-angle scattering from the dusk side to the dawn side could be tracked in the ENA images, as the ions producing these ENAs transited the inner magnetosphere while en route to being lost through the magnetopause.

\section{Summary and conclusions}

This paper presents early results from the ENA imager NUADU on board Double Star-Polar (TC-2). Two examples of ENA imaging are illustrated and discussed. Conclusions are as follows:

1. NUADU imaged the high-altitude ring current during both a moderate and a major geomagnetic storm in the $\sim 50-158 \mathrm{keV}$ range, with a time resolution of $\sim 10 \mathrm{~min}$.
2. Images recorded during south polar perigee passes in the early recovery phase of a moderate magnetic storm in September 2004, showed bright ENA emissions at the feet of disturbed terrestrial magnetic field lines, due to an associated strong increase in the flux of energetic charged particles present in the radiation belts. These emissions were long lived and followed, through intensity variations, even minor changes in the Dst index. The time resolution of these low-altitude emissions was $16 \mathrm{~s}$.

3. An ENA image of the ring current recorded on 8 November 2004 (in the course of an episode of southward turning of the interplanetary magnetic field and in the early recovery phase of a major geomagnetic storm), shows classical enhanced emissions in the local midnight through the dusk sector, indicating that ions were injected on the nightside into the inner magnetosphere.

4. ENA data recorded simultaneously aboard TC2/NUADU and IMAGE/HENA (which, respectively, viewed the Northern and Southern Hemispheres during a major magnetic storm on 8 November 2004, close 


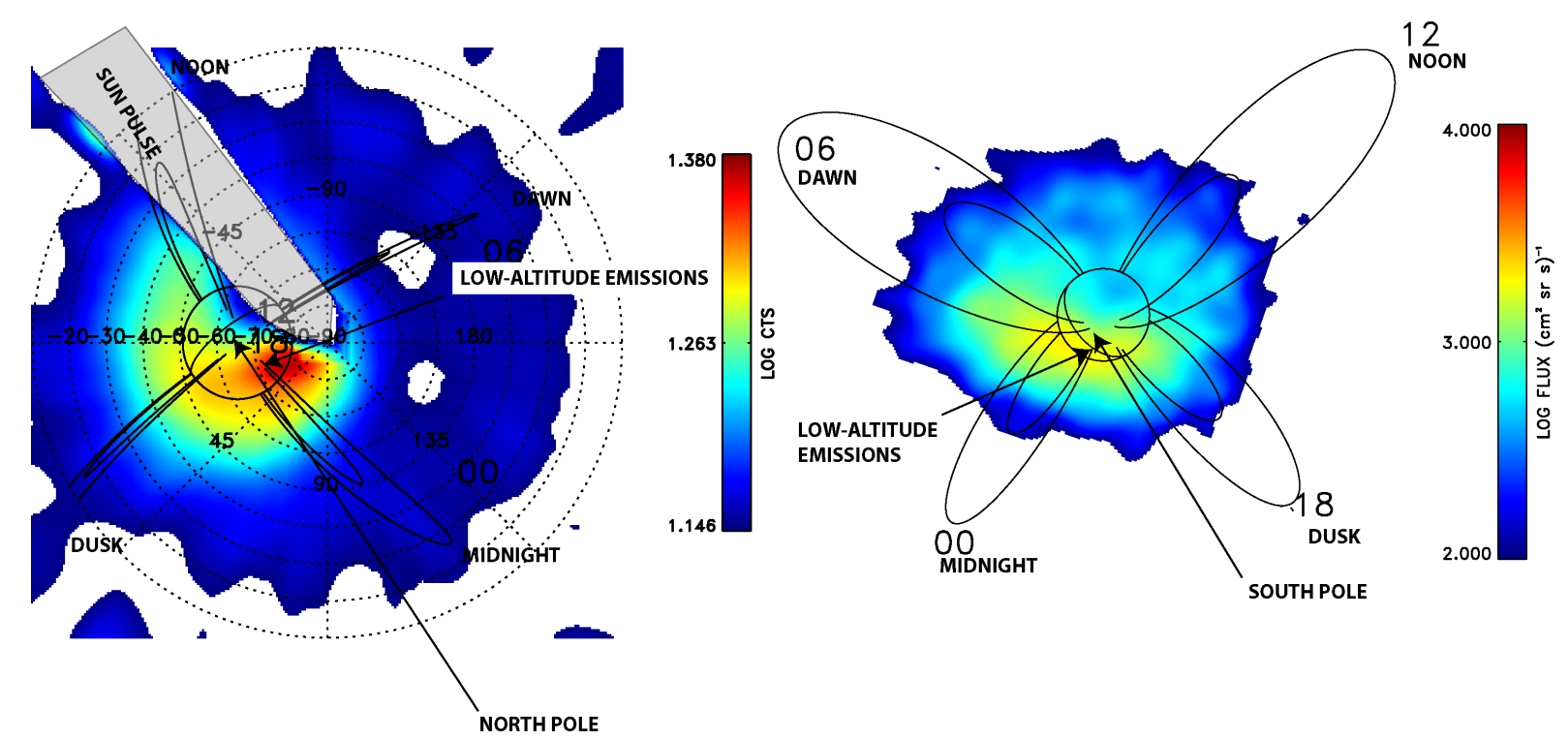

Fig. 23. (Left) ENA image obtained by NUADU/TC-2 in the 81-158 keV range from 10:10-11:03 UT on 8 November 2004 . Note that this image was taken over the North Pole; (right) ENA image obtained simultaneously by HENA/IMAGE in the 60-119 keV range taken over the South Pole. In both images, the ring current can be seen extending from local midnight through dusk.

to the maximum phase of ring current development), show similar topology. A comparison between these records indicated that the NUADU ring-current image was recorded in protons.

5. Pitch-angle scattering processes which cause equatorially trapped protons $(\mathrm{L}>5)$ to precipitate to lower latitudes, were activated during the main phase of the magnetic storm of November 2004. The region of enhanced pitch-angle scattering shifted from the dusk side to the dawn side during the main phase of the storm.

6. Records obtained in ENAs of the ring current by NUADU show that the pattern of flare-related ion precipitation was closely reflected in the ENA data. In particular, a shift in the region of enhanced pitch-angle scattering from the dusk side to the dawn side could be traced in the ENA images.

Acknowledgements. S. McKenna-Lawlor thanks Enterprise Ireland for support that enabled the building of the NUADU instrument. Also, K. Kudela wishes to acknowledge support from the VEGA Grant Agency (Project 4064). The team acknowledges with appreciation the provision by W. Murtagh/SEC, NOAA of various solar records compared in this paper with the ENA data.

Topical Editor T. Pulkkinen thanks two referees for their help in evaluating this paper.

\section{References}

Asamura, K., Mukai, T., Saito, Y., Kazama, Y., and Maschida, S.: First measurement of $\sim 10 \mathrm{keV}$ neutral atoms in the low-latitude ionosphere, Geophys. Res. Lett., 26, 33-36, 1999.
Baker, D. N.: Telescopic and microscopic views of the magnetosphere: multispacecraft observations, Space Sci. Rev., 109, 133153, 2003.

Baker, D. N., Pulkkinen, T. I., Angelopoulos, V., Baumjohann, W., and McPherron, R. L.: Neutral line model of substorms: Past results and present view, J. Geophys. Res., 101, 12 975-13010, 1996.

Baker, D. N., Pulkkinen, T. I., Hesse, M., and McPherron, R. L.: A quantitative assessment of energy storage and release in the Earth's magnetotail, J. Geophys. Res., 102, 7159-7168, 1997.

Barabash, S., Brandt, P. C., Norberg, O., Lundin, R., Roelof, E. C., Chase, C. J., Mauk, B. H., and Koskinen, H.: Energetic Neutral Atom Imaging by the Astrid microsatellite, Adv. Space Res., 20, 1055-1060, 1997.

Baumjohann, W.: The near Earth plasma sheet: An AMPTE/IRM perspective, Space Sci. Rev., 64, 141-163, 1993.

Blake, J. B., Fennell, J. F, Friesen, L. M., Johnson, B. M., Kolasnski, W. A., Mabry, D. J., Osborn, J. W.,Penzin, S. H., Schnauss, E. R., Spence, H. E., Baker, D. N., Belian, R., Fritz, T. A,, Ford, W., Laubscher, B., Stiglich, R., Baraze, R. A., Hilsenrath, M. F., Imhof, W. M., Kilner, J. R., Moblia, J., Voss, D. H., Korth, A., Gull, M., Fisher, K., Grande, M., and Hall, D.: CEPPAD, Comprehensive Energetic Particle and Pitch Angle Distribution Experiment on POLAR, Space Sci. Rev., 71, 531-562, 1995.

Brandt, P. C., Barabash, S., Norberg, O., Lundin, R., Roelof, E. C., and Chase, C. J.: ENA imaging at low altitudes from the Swedish micro-satellite Astrid: images and spectral analysis, J. Geophys. Res., 104, 2367-2379, 1999.

Brandt, P. C., Barabash, S., Roelof, E. C., and Chase, C. J.: Energetic neutral atom imaging at low altitudes from the Swedish micro-satellite Astrid: Extraction of the equatorial ion distribution, J. Gephys. Res. 105, 25 731-25 744, 2001.

Brandt, P. C., Ohtani, S., Mitchell, D. G., Fok, M. C., Roelof, E. C., and Demajistre, R.: Global ENA observations of the storm mainphase ring current: implications for skewed electric fields in the 
inner magnetosphere, Geophys. Res. Lett, 3-18, $2002 \mathrm{a}$.

Brandt, P. C., Demajistre, R., Roelof, E. C., Mitchell, D. G., and Mende, S.: IMAGE/HENA: Global ENA imaging of the plasma sheet and ring current during substorms, J. Geophys. Res., 107(A12), 1454, doi:10.1029/2002JA009307, 2002b.

Brandt, P. C., Mitchell, D. G., Ohtani, S., DeMajistre, R., Roelof, E. C., Jahn, J.-M., Pollock, C. J., and Reeves, G.: Storm-substorm relationship during the 4 October 2000 storm. IMAGE global ENA imaging results, AGU Geophys. Monogr., 42, 103-118, 2003.

Burch, J. L.: The First Two Years of Image, Space Sci. Rev., 109, $1-24,2003$.

Burch, J. L., Schulz, M., and Spence, H. (Eds): Preface: Inner magnetosphere interactions: New perspectives from imaging, Geophys. Monogr. Ser. (Publ. American Geophysical Union), 159, vii-viii, 2005.

Daglis, I. A.: The role of magnetosphere-ionosphere coupling in magnetic storm dynamics, in: Magnetic Storms, edited by: Tsurutani, B. T., Gonzalez, W. D., Yanide, Y., and Arballo, J. K., Geophys. Monogram Ser., 98, (Publ. Amer. Geophys. Union), 107-116, 1997.

Daglis, I. A.: Space Storms, Ring Current and Space-Atmosphere Coupling, in: Space Storms and Space Weather Hazards, Chapter 1, edited by: Daglis, I. A., Kluwer Academic Publ., 1-42, 2001.

Daglis, I. A., Thorne, R. M., Baumjohann, W., and Orsini, S.: The terrestrial ring current: Origin, formation and decay, Rev. Geophys., 37, 407-438, 1999.

Delcourt, D. C.: Particle acceleration by inductive electric fields in the inner magnetosphere, J. Atmos. Solar-Terr. Phys., 64, 551$559,2002$.

Demajistre, R., Roelof, E. C., Brandt, P. C., and Mitchell, D.G.: Retrieval of global magetospheric ion distributions from high energy neutral atom (ENA) measurements made by the IMAGE/HENA instrument, J. Geophys. Res., 109, A04214, doi:10.1029/2003JA010322, 2004

De Michelis, P. and Orsini, S.: Energetic Neutral atoms propagating toward the Earth: analysis of the reduction rate due to ionospheric and atmospheric interactions, J, Geophys. Res., 102, 185-193, 1997.

Dessler, A. J. and Parker, E. N.: Hydromagnetic theory of geomagnetic storms, J. Geophys. Res., 64, 2239-2252, 1959.

Fok, M. C., Wolf, R. A., Spiro, R. W., and Moore, T. E.: Comprehensive computational model of the Earth's ring current, J. Geophys. Res., 106(A5), 8417-8424, 2001.

Fok, M. C., Moore, T. E., Wilson, G. R., Perez, J. D., Zhang, X. X., Brandt, P. C., Mitchell, D. G., Roelof, E. C., Jahn, J.-M., Pollock, C. J., and Wolf, R. A.: Global ENA image simulations, Space Sci. Rev., 109, 77-103, 2003.

Friedel, R., Reeves, R., and Ohara, T.: Relativisitc electron dynamics in the inner magnetosphere - a Review, J. Atmos. Solar. Terr. Phys., 64, 265-282, 2002

Hamilton, D. C., Gloeckler, G., Ipavich, F. M., Stüdemann, W., Wilken, B., and Kremser, G.: Ring current development during the great geomagnetic storm of February 1986, J. Geophys. Res, 93, 14343-14355, 1988.

Henderson, M. G., Reeves, G. D., Spence, H. E., Sheldon, R. B., Jorgensen, A. M., Blake, J. B., and Fennell, J. F.: First energetic neutral atom images from Polar, Geophys. Res. Lett., 24, 11671170, 1997.

Hendersen, M. G., Reeves, G. D., Jorgensen, A. M., Spence, H. E., Frank, L. A., Sigwarth, J. B., Fennell, J. F., Roeder, J. L., Blake, J. B., Yumoto, K., and Bourdarie, S.: POLAD CEPAD/IPS en- ergetic neutral atom (ENA) images of a substorm injection, Adv. Space Sci., 25, No. 12, 2407-2416, 2000.

Jorgensen, A. M., Spence, H. E., Henderson, M. G., Reeves, G. D., Sugiura, M., and Kamei, T.: Global energetic neutral atom (ENA) measurements and their association with the Dst index, Geophys. Res. Lett., 24, 3173-3176, 1997.

Kamide, Y., Yokoyama, N., Gonzalez, W. D., Tsurutani, B. T., Daglis, I. A., Brekke, A., and Masuda, S.: Two-step development of geomagnetic storms, J. Geophys. Res., 103, 6917-6921, 1998a.

Kamide, Y., Baumjohann, W., Daglis, I. A., Gonzalez, W. D., Grande, M., Joselyn, J. A., McPherron, R. L., Phillips, J. L., Reeves, E. G. D., Rostoker, G., Sharma, A. S., Singer, H. J., Tsurutani, B. T., and Vasyliunas, V. M.: Current understanding of magnetic storms: Storm/substorm relationships, J. Geophys. Res. 103, 17 705-17 728, 1998b.

Kivelson, M. G. and Russell, C. T.: Introduction to Space Physics, Publ. Cambridge Univ. Press, New York, 1995.

Kozyra, J. U. and Liemohn, M. W.: Ring current energy input and decay, Space Sci. Rev., 109, 105-131, 2003, reprinted in: Magnetospheric Imaging, The Image Prime Mission, edited by: Burch, J. L., Kluwer Acad. Publ., 2003.

Kozyra, J. U., Borovsky, J. E., Chen, M. W., Fok, M.-C., and Jordanova, V. K.: Plasma sheet pre-conditioning, enhanced convection and ring current development, in: Substorms-4., edited by: Kokubun, S. and Kamide, Y., Sci. Publ, Co./Kluwer Acad. Publ., $755,1998$.

Krimigis, S. M., Mitchell, D. G., Hamilton, D. C., Livi, S., Dandouras, I., Jaskulek, S., Armstrong, T. P., Boldt, J. D., Cheng, A. F., Gloeckler, G., Hayes, J. R., Hsieh, K. C., Ip, W.-H., Keath, E. P., Kirsch, E., Krupp, N., Lanzerotti, L. J., Lundgren, R., Mauk, B. H., McEntire, R. W., Roelof, E. C., Schlemm, C. E., Tossman, B. E., Wilken, B., and Williams, D. J.: Magnetospheric Imaging Instrument (MIMI) on the Cassini Mission to Saturn/Titan, Space Sci. Rev., 114, 233-329, doi:10.1007/s11214004-1410-8, 2004.

Lui, A. T. Y.: A synthesis of magnetospheric substorm models, J. Geophys. Res., 96, 1849-1856, 1991.

Lui, A. T. Y., Williams, D. J., McEntire, R. W., and Roelof, E. C.: First composition measurements of energetic neutral atoms, Geophys. Res. Lett., 23, 2641-2644, 1996.

McEntire, R. W. and Mitchell, D. G.: Instrumentation for global magnetospheric imaging of energetic neutral atoms, in: Solar System Plasma Physics, edited by: Waite Jr., J. H., Burch, J. L., and Moore, T. E., Geophys. Monograph, 54, 69-80, 1989.

McKenna-Lawlor, S., Balaz, J., Strharsky, I., Barabash, S., Johnsson, K., Li, L., Cao, J. B., Shen, C., Zong, Q., Roelof, E. C., Brandt, P., Kudela, K., Fu, S., and Dandouras, I.: The energetic NeUtral Atom Detector Unit (NUADU) for China's Double Star Mission and its calibration, Nucl. Inst. \& Methods in Phys. Res., A 530, 311-322, 2004

McKenna-Lawlor, S., Balaz, J., Strharsky, I., Barabash, S., Johnsson, K., Li, L., Cao, J. B., Chao, S., Zong, Q., Roelof, E. C., Brandt, P., Kudela, K., Fu, S., and Dandouras, I.: An overview of the scientific objectives and technical configuration of the Neutral Atom Detector Unit NUADU on the Chinese Double Star Mission, Planet. Space Sci., 53, 335-348, 2005.

McPherron, R. L.: The role of substorms in the generation of magnetic storms, in: Magnetic Storms, edited by: Tsurutani, B. T. Gonzalex, W. D., Kamide, Y., and Arballo, J. K., Geophys. Monograph, Publ. AGU, Washington, 98, 131-147, 1997.

Mitchell, D. G., Jaskulek, S. E., Schlemm, C. H., Keath, E. P., 
Thompson, R. B., Tossman, B. E., Boldt, J. D., Hayes, J. R., Andrews, G. B., Paschalidis, N., Hamilton, D. C., Lundgren, R. A., Tums, E. O., Wilson, P. I, Voss, H. D., Prentice, D., Hsieh, K. C., Curtis, C. C., and Powell, F. R.: High energy neutral atom HENA imager for the IMAGE mission, Space Sci. Rev., 91, 67-112, 2000.

Mitchell, D. G., Brandt, P. C., Roelof, E. C., Hamilton, D. C., Retterer, K. C., and Mende, S.: Global imaging from IMAGE/HENA, Space Sci. Rev. 109, 63-75, 2003.

Moore, T. E., Chandler, M. O., Fok, M.-C., Giles, B. L., Delcourt, D. C., Horwitz, J. L., and Pollock, C. J.: Ring currents and internal plasma sources, Space Sci. Rev., 95, 555-568, 2001.

Northrop, T. G.: The adiabatic motion of charged particles, Publ. Interscience, New York, 1963.

Ohtani, S., Fujii, R., Hesse, M., and Lysak, R. L. (Eds.): In Magnetospheric Current Systems, Geophys. Monogr. Ser., Publ. American Geophysical Union, 118, 2000.

Orsini, S., Milillo, A., Daglis, I. A., and Livi, S.: Simulation of ENA fluxes along the Geotail Spacecraft Orbit, J. Atmos. Solar Terr. Phys., 62, 919-926, 2000.

Perez, J. D., Fok, M.-C., and Moore, T. E.: Deconvolution of energetic neutral atom images of the Earth's magnetosphere, Space Sci. Rev., 91, 421-436, 2000.

Perez, J. D., Kozlowski, G., Brandt, P. C., Mitchell, D. G., Jahn, J. M., Pollock, C. J., and Zhang, X.: Initial ion equatorial pitch angle distributions from energetic neutral atom images obtained by IMAGE, Geophys. Res. Lett., 28, 1155-1158, 2001.

Pollock, C. J., Brandt, P. C., Burch, J. L., Henderson, M. G., Jahn, J.-M., McComas, D. J., Mende, S. B., Mitchell, D. G., Reeves, G. D., Scime, E. E., Skoug, R. M., Thomsen, M., and Valek, P.: The role and contributions of energetic neutral atom (ENA) imaging in magnetospheric substorm research, Space Sci. Rev., 109, 155-182, 2003.

Pulkkinen, T., Tsyganenko, N. A., Reiner, H., and Friedel, W. (Eds).: In The Inner Magnetosphere: Physics and Modelling, Geophys. Monogr. Ser., Publ. American Geophysical Union, 155, 2005.

Reeves, G. D. and Henderson, M. G.: The storm-substorm relationship: Ion injections in geosynchronous measurements and composite energetic neutral atom images, J. Geophys. Res., 106, 5833-5844, 2001.

Reeves, G. D., Henderson, M. G., Skoug, R. M., Thomsen, M. F., Borovsky, J. E., Funsten, H. O., C:son Brandt, P., Mitchell, D. J., Jahn, J.-M., Pollock, C. J., McComas, D. J., and Mende, S. B.: IMAGE, POLAR and geosynchronous observations of substorm and ring current ion injection, AGU Monograph 142 on the Storm-Substorm relationship, 2004.

Rème, H., Aoustin, C., Bosqued, J. M., Dandouras, I., Lavraud, B., Sauvaud, J. A., Barthe, A., Bouyssou, J., Camus, Th., CoeurJoly, O., Cros, A., Cuvilo, J., Ducay, F., Garbarowitz, Y., Medale, J. L., Penou, E., Perrier, H., Romefort, D., Rouzaud, J., Vallat, C., Alcayd, D., Jacquey, C., Mazelle, C., dUston, C., Mbius, E., Kistler, L. M., Crocker, K., Granoff, M., Mouikis, C., Popecki, M., Vosbury, M., Klecker, B., Hovestadt, D., Kucharek, H., Kuenneth, E., Paschmann, G., Scholer, M., Sckopke, N., Seidenschwang, E., Carlson, C. W., Curtis, D. W., Ingraham, C., Lin, R. P., McFadden, J. P., Parks, G. K., Phan, T., Formisano, V., Amata, E., Bavassano-Cattaneo, M. B., Baldetti, P., Bruno, R., Chionchio, G., Di Lellis, A., Marcucci, M. F., Pallocchia, G., Korth, A., Daly, P. W., Graeve, B., Rosenbauer, H., Vasyliunas, V., McCarthy, M., Wilber, M., Eliasson, L., Lundin, R., Olsen, S., Shelley, E. G., Fuselier, S., Ghielmetti, A. G., Lennartsson, W., Es- coubet, C. P., Balsiger, H., Friedel, R., Cao, J-B., Kovrazhkin, R. A., Papamastorakis, I., Pellat, R., Scudder, J., and Sonnerup, B.: First multispacecraft ion measurements in and near the Earth's magnetosphere with the identical Cluster ion spectrometry (CIS) experiment, Ann. Geophys., 19, 1303-1354, 2001,

SRef-ID: 1432-0576/ag/2001-19-1303.

Roederer, J. G.: Dynamics of Geomagnetically Trapped Radiation, Publ. Springer, Berlin, Heidelberg, New York, 1971.

Roelof, E. C.: Energetic Neutral Atom image of a storm time ring current, Geophys. Res. Lett, 14, 652-655, 1987.

Roelof, E. C.: Remote sensing of the ring current using energetic neutral atoms, Adv. Space Res., 9, 12, 12 195-12 203, 1989.

Roelof, E. C.: Energetic neutral atom imaging of magnetospheric ions from high- and low-altitude spacecraft, Adv. Space Res., 20, 341-350, 1997a.

Roelof, E. C.: ENA emissions from nearly mirroring magnetospheric ions interacting with the exobase, Adv. Space Res., 20, 361-366, 1997b.

Roelof, E. C. and Skinner, A. J.: Extraction of ion distributions from magnetospheric ENA and EUV images, Adv. Space Res., 91, 437-459, 2000.

Roelof, E. C., Mitchell, D. G., and Mitchell, D. J.: Energetic neutral atoms $(\mathrm{E} \sim 50 \mathrm{keV})$ from the ring current: IMP $7 / 8$ and ISEE-1, J. Geophys. Res., 90, No. A11, 10 991-11 008, 1985.

Schulz, M. and Lanzerotti, L. J.: Particle Diffusion in the Radiation Belts, Springer, Berlin, Heidelberg, New York, 1974.

Sckopke, N.: A general relation between the energy of trapped particles and the disturbance field near the Earth, J. Geophys. Res., 71, 3125-3130, 1966.

Sharma, A. S., Kamide, Y., and Lakhina, G. S.: Disturbances in Geospace: The Storm-Substorm relationship, Geophys. Monogr. Ser., 142, 2004.

Singer, S. F.: A new model of magnetic storms and aurorae, Trans. AGU (later renamed Eos), 38, 175-190, 1957.

Spjeldvik, W. N. and Rothwell, P. L.: The Radiation Belts, in: Handbook of Geophysics and the Space Environment, edited by: Jursa, A. S., Airforce Geophys. Lab. Hanscom AFB, MA, ADA 167 000, USA, Chapter 5, 546-550, 1985.

Tsurutani, B. T., Gonzalez, W. D., Kamide, Y., and Arballo, J. K (Eds.): The interplanetary causes of magnetic storms: A Review, in: Magnetic Storms, Geophys. Monogr. Ser., 98, 1997.

Tsyganenko, N. A., Singer, H. J., and Kasper, J. C.: Storm-time distortion of the inner magnetosphere: How severe can it get?, J. Geophys. Res., 108, SMP 18-1 to SMP 18-15, 2003.

Vallat, C., Dandouras, I., Brandt, P. C., Mitchell, D. G., Roelof, E. C., deMajistre, R., Rème, H., Sauvaud, J.-A., Kistler, L., Mouikis, C., Dunlop, M., and Balogh, A.: First comparisons of local ion measurements in the inner magnetosphere with ENA magnetospheric image inversions: Cluster-CIS and IMAGE-HENA observations, J. Geophys. Res., 109, A04213, doi:10.1029/2003JA010224, 2004.

Voss, H. D., Hertzberg, E., Ghielmetti, A. G., Battel, S. J., Appert, K. L., Higgins, B. R., Murray, D. O. and Vondrak, R.: Medium Energy Ion Mass and Neutral Atom Spectrometer, J. Spacecraft \& Rockets, 29, No. 4, 566-569, 1992.

Voss, H. D., Mobilia, J., Collin, H. L., and Inhof, W. L.: Satellite observations and instrumentation for measuring energetic neutral atoms, Opt. Eng., 32, 3083-3089, 1993.

Wilken, B., Daglis, I. A., Milillo, A., Orsini, S., Doke, T., Livi, S., and Ullaland, S.: Energetic neutral atoms in the outer magnetosphere: An upper flux limit obtained with the HEP-I.D spectrometer on board GEOTAIL, Geophys. Res. Lett., 24, 111-114, 
$1997 \mathrm{a}$.

Wilken, B., Axford, W. I., Daglis, I., Daly, P., Guttler, W., Ip, W.H., Korth, A., Kremser, G., Livi, S., Vasyliunas, V. M., Woch, J., Baker, D., Belian, R. D., Blake, B. B., Fennell, J. F., Lyons, I. R., Borg, H., Fritz, T. A., Gliem, F., Rathje, R., Grande, M., Hall, D., Kecskemety, K., McKenna-Lawlor, S., Mursula, K. Tanskanen, P., Pu, Z., Sandahl, I., Sarris, E. T., Scholer, M., Schulz, M., Sorass, P., and Ullalund, S.: RAPID, The Imaging Energetic Particle Spectrometer on Cluster, Space Sci. Rev., 79, 399-473, 1997b.
Williams, D. J., Keppler, E., Fritz, T. A., and Wilken, B.: The ISEE 1 and 2 medium energy particles experiment, IEEE Trans. Geosci. Electron., Vol. GE-16, No. 3, 270-280, 1978.

Wygant, J., Rowland, D., Singer, H. J., Temerin, M., Mozer, F., and Hudson, M. K.: Experimental evidence on the role of the large spatial scale electric field in creating the ring current, J. Geophys. Res., 103, 29 527-29 544, 1998.

Young, D. T., Balsiger, H., and Geiss, J.: Correlations of magnetospheric ion composition with geomagnetic and solar activity, J. Geophys. Res., 87, 9077-9096, 1982. 